\title{
Species recovery and recolonization of past habitats: lessons for science and conservation from sea otters in estuaries
}

Brent B Hughes ${ }^{\text {Corresp., } 1,2}$, Kerstin Wasson ${ }^{3,4}$, M. Tim Tinker ${ }^{4,5}$, Susan L Williams ${ }^{6}$, Lilian P Carswell ${ }^{7}$, Katharyn E Boyer $^{8}$, Michael W Beck ${ }^{9}$, Ron Eby $^{3}$, Robert Scoles ${ }^{3}$, Michelle Staedler ${ }^{10}$, Sarah Espinosa ${ }^{4}$, Margot Hessing-Lewis ${ }^{11}$, Erin U Rechsteiner ${ }^{11}$, Kathryn Beheshti ${ }^{4}$, Tracy M Grimes ${ }^{12}$, Benjamin H Becker ${ }^{13}$, Lisa Needles ${ }^{14}$, Joseph A Tomoleoni $^{5}$, Jane Rudebusch ${ }^{8}$, Ellen Hines ${ }^{8}$, Brian R Silliman ${ }^{2}$

1 Department of Biology, Sonoma State University, Rohnert Park, California, United States of America

2 Division of Marine Science and Conservation, Nicholas School of the Environment, Duke University, Beaufort, North Carolina, United States of America

3 Elkhorn Slough National Estuarine Research Reserve, Watsonville, California, United States of America

4 Department of Ecology and Evolutionary Biology, University of California, Santa Cruz, Santa Cruz, California, United States

5 Western Ecological Research Center, United States Geological Survey, Santa Cruz, California, United States of America

6 Department of Evolution and Ecology, Bodega Marine Laboratory, University of California, Davis, Bodega Bay, California, United States of America

7 Ventura Fish and Wildlife Office, United States Fish and Wildlife Service, Ventura, California, United States of America

8 Estuary \& Ocean Science Center, San Francisco State University, Tiburon, California, United States of America

9 Institute of Marine Sciences, University of California, Santa Cruz, Santa Cruz, California, United States of America

10 Monterey Bay Aquarium, Monterey, California, United States of America

11 Hakai Institute, Heriot Bay, British Columbia, Canada

12 Department of Biology, San Diego State University, San Diego, California, United States of America

13 Point Reyes National Seashore, United States National Park Service, Point Reyes Station, California, United States of America

14 Center for Coastal Marine Sciences, California Polytechnic State University - San Luis Obispo, San Luis Obispo, California, United States of America

Corresponding Author: Brent B Hughes

Email address: hughes@sonoma.edu

Recovering species are often limited to much smaller areas than they historically occupied. Conservation planning for the recovering species is often based on this limited range, which may simply be an artifact of where the surviving population persisted. Southern sea otters (Enhydra lutris nereis) were hunted nearly to extinction but recovered from a small remnant population on a remote stretch of the California outer coast, where most of their recovery has occurred. However, studies of recently-recolonized estuaries have revealed that estuaries can provide southern sea otters with high quality habitats featuring shallow waters, high production and ample food, limited predators, and protected haul-out opportunities. Moreover, sea otters can have strong effects on estuarine ecosystems, fostering seagrass resilience through their consumption of invertebrate prey. Using a combination of literature reviews, population modeling, and prey surveys we explored the former estuarine habitats outside the current southern sea otter range to determine if these estuarine habitats can support healthy sea otter populations. We found the majority of studies and conservation efforts have focused on populations in exposed, rocky coastal 
habitats. Yet historical evidence indicates that sea otters were also formerly ubiquitous in estuaries. Our habitat-specific population growth model for California's largest estuary San Francisco Bay - determined that it alone can support about 6600 sea otters, more than double the 2018 California population. Prey surveys in estuaries currently with (Elkhorn Slough and Morro Bay) and without (San Francisco Bay and Drakes Estero) sea otters indicated that prey availability, especially crab are sufficient to support healthy sea otter populations. When combining historical evidence with our results we show that conservation practitioners should consider former estuarine habitats as targets for sea otter and ecosystem restoration. This study reveals the importance of understanding how recovering species interact with all the ecosystems they historically occupied, both for improved conservation of the recovering species and for successful restoration of ecosystem functions and processes. 


\section{Species recovery and recolonization of past habitats: lessons for science and conservation from sea otters in estuaries}

Brent B. Hughes ${ }^{1,2}$, Kerstin Wasson ${ }^{3,4}$, M. Tim Tinker ${ }^{3,5}$, Susan L. Williams ${ }^{6, \omega}$, Lilian P.

Carswell 7 , Katharyn E. Boyer ${ }^{8}$, Michael W. Beck ${ }^{9}$, Ron Eby $^{4}$, Robert Scoles ${ }^{4}$, Michelle

Staedler ${ }^{10}$, Sarah Espinosa ${ }^{3}$, Margot Hessing-Lewis ${ }^{11}$, Erin U. Rechsteiner ${ }^{11}$, Kathryn Beheshti ${ }^{3}$, Tracy M. Grimes ${ }^{12}$, Benjamin H. Becker ${ }^{13}$, Lisa Needles ${ }^{14}$, Joseph A. Tomoleoni ${ }^{5}$, Jane

Rudebusch $^{8}$, Ellen Hines ${ }^{8}$, Brian R. Silliman ${ }^{2}$

${ }^{1}$ Department of Biology, Sonoma State University, Rohnert Park, CA, U.S.A.

${ }^{2}$ Division of Marine Science and Conservation, Nicholas School of the Environment, Duke University, Beaufort, NC, U.S.A.

${ }^{3}$ Department of Ecology and Evolutionary Biology, University of California Santa Cruz, Santa Cruz, CA, U.S.A.

${ }^{4}$ Elkhorn Slough National Estuarine Research Reserve, Watsonville, CA, U.S.A

${ }^{5}$ Western Ecological Research Center, United States Geological Survey, Santa Cruz, CA, U.S.A.

${ }^{6}$ Department of Evolution and Ecology, University of California Davis, Bodega Marine Laboratory, Bodega Bay, CA, U.S.A.

${ }^{7}$ Ventura Fish and Wildlife Office, United States Fish and Wildlife Service, Ventura, CA, U.S.A.

${ }^{8}$ Estuary \& Ocean Science Center, San Francisco State University, Tiburon, CA, U.S.A.

${ }^{9}$ Institute of Marine Sciences, University of California Santa Cruz, Santa Cruz, CA, U.S.A.

${ }^{10}$ Monterey Bay Aquarium, Monterey, CA, U.S.A

${ }^{11}$ Hakai Institute, Heriot Bay BC, Canada

${ }^{12}$ Department of Biology, San Diego State University, San Diego, CA, U.S.A.

${ }^{13}$ United States National Park Service, Point Reyes National Seashore, Point Reyes Station, CA, U.S.A.

${ }^{14}$ Center for Coastal Marine Sciences, California Polytechnic State University - San Luis

Obispo, San Luis Obispo, CA, U.S.A.

${ }^{\omega}$ Deceased 
47 Corresponding author:

48 Brent B. Hughes

491801 E. Cotati Ave.

50 Rohnert Park, CA 94928

51 hughes@sonoma.edu

\section{Abstract}

54 Recovering species are often limited to much smaller areas than they historically occupied.

55 Conservation planning for the recovering species is often based on this limited range, which may

56 simply be an artifact of where the surviving population persisted. Southern sea otters (Enhydra

57 lutris nereis) were hunted nearly to extinction but recovered from a small remnant population on

58 a remote stretch of the California outer coast, where most of their recovery has occurred.

59 However, studies of recently-recolonized estuaries have revealed that estuaries can provide

60 southern sea otters with high quality habitats featuring shallow waters, high production and

61 ample food, limited predators, and protected haul-out opportunities. Moreover, sea otters can

62 have strong effects on estuarine ecosystems, fostering seagrass resilience through their

63 consumption of invertebrate prey. Using a combination of literature reviews, population

64 modeling, and prey surveys we explored the former estuarine habitats outside the current

65 southern sea otter range to determine if these estuarine habitats can support healthy sea otter

66 populations. We found the majority of studies and conservation efforts have focused on

67 populations in exposed, rocky coastal habitats. Yet historical evidence indicates that sea otters

68 were also formerly ubiquitous in estuaries. Our habitat-specific population growth model for

69 California's largest estuary - San Francisco Bay - determined that it alone can support about

706600 sea otters, more than double the 2018 California population. Prey surveys in estuaries

71 currently with (Elkhorn Slough and Morro Bay) and without (San Francisco Bay and Drakes

72 Estero) sea otters indicated that prey availability, especially crab are sufficient to support healthy 
73 sea otter populations. When combining historical evidence with our results we show that

74 conservation practitioners should consider former estuarine habitats as targets for sea otter and

75 ecosystem restoration. This study reveals the importance of understanding how recovering

76 species interact with all the ecosystems they historically occupied, both for improved

77 conservation of the recovering species and for successful restoration of ecosystem functions and

78 processes.

79

\section{Introduction}

Widespread declines of top predator populations have profoundly altered ecological

relationships, resulting in the degradation or collapse of many ecosystems (Jackson et al., 2001;

83 Estes et al., 2011; Ripple et al., 2014). Because many of these losses occurred well before

84 systematic ecological studies could document their effects, our understanding of ecological

85 baselines has been fundamentally skewed (Jackson et al., 2001). Sea otters (Enhydra lutris)

86 provide an excellent example of a top predator whose decline has dramatically altered ecological

87 relationships as a keystone predator. Coastal habitats along the North Pacific Rim between

88 Hokkaido, Japan and central Baja California, Mexico formerly supported large numbers of sea

89 otters, but the fur trade of the eighteenth and nineteenth centuries reduced sea otter numbers

90 worldwide from an estimated 150,000-300,000 pre-exploitation (Kenyon 1969, Johnson 1982) to

91 approximately 2,000 post-exploitation (Kenyon 1969). Northern sea otter (E. lutris kenyoni)

92 populations around Washington, British Columbia and Southeast Alaska have benefitted from

93 successful reintroductions, whereas in other places natural population range expansion has

94 ceased (i.e., southern sea otters - E. lutris nereis - in California), or is in a state of decline, such

95 as southwest Alaska (Bodkin, 2015). As sea otters have recovered from near extinction over the 
96 past decades, they have been the subject of intensive research aimed at furthering their recovery

97 and understanding more fully their role as keystone predators in coastal ecosystems.

While sea otters are closely associated with kelp forests, historical and paleoecological

99 evidence makes clear that southern sea otters were once abundant in California estuaries.

100 Archaeological sites from central California estuaries suggest that Native Americans hunted sea

101 otters, as their bones have often been found in middens throughout San Francisco Bay, Drakes

102 Estero, Elkhorn Slough, and Morro Bay, representing a period spanning most of the last 7000

103 years (Broughton 1999; Jones et al. 2011, Pt. Reyes National Seashore Museum Collections)

104 (Fig. 1A). In the largest of these middens in the San Francisco Bay area (Fig. 2A), the

105 Emeryville Shellmound, sea otter skeletal remains were the most abundant among a wide variety

106 of other mammalian skeletal remains (Schenck, 1926). Schenck (1926) noted that sea otters

107 "occurred at all depths" of the shellmound, and that they were "of prime importance in the

108 economy of the inhabitants."

109 Early accounts by Spanish explorers documented sea otters' widespread use of San

110 Francisco Bay, ranging from San Jose in the south to Richardson Bay in the north (Fig. 2A).

111 Ogden (1941) notes, "San Francisco Bay abounded in otters. Apparently, they not only swam

112 around in the bay but frequented the numerous estuaries and even hauled up on the shore." Sea

113 otters probably numbered in the thousands in this estuary prior to being driven to local extinction

114 by over-hunting (Schenck, 1926). The Aleut (Alaskan Native Americans), who were much more

115 skilled otter hunters than the Ohlone (California Native Americans), were forced to join

116 European hunting expeditions and were capable of killing and retrieving hundreds of sea otters

117 daily from San Francisco Bay (Ogden, 1941).

118 
120 fewer than 50 individuals was reported in 1914 near Pt. Sur along the rugged Big Sur coast in

121 California (Bryant, 1915). As of 2018, this population has grown to over 3,000 individuals and

122 has expanded its geographic range to include more than $400 \mathrm{~km}$ of coastline (Tinker \& Hatfield,

123 2018). Southern sea otter numbers are approaching the recovery criterion established by the U.S.

124 Fish and Wildlife Service for delisting consideration under the Endangered Species Act (U.S.

125 Fish and Wildlife Service, 2003), but they are far below their estimated carrying capacity of

126 approximately 16,000 for California (Laidre, Jameson \& DeMaster, 2001) and remain restricted

127 to a fraction of their historic range (U.S. Fish and Wildlife Service, 2003; Lafferty \& Tinker,

128 2014). Because the initial recovering population occurred in kelp forests along the open coast

129 throughout the sea otter range, foundational studies on the ecology of sea otters have focused on

130 this habitat (Lowry \& Pearse, 1973; Estes \& Palmisano, 1974; Simenstad, Estes \& Kenyon,

131 1978). This lack of baseline knowledge has been seen for other top predators around the world

132 who rather than occupying seemingly unique habitats for the first time, are in fact reoccupying

133 historical habitat (Silliman et al., 2018). As a result of historical accident (i.e., the location of the

134 surviving population), sea otters in California have become closely associated with kelp forests

135 in the minds of both the public and scientists. However, southern sea otters historically occupied

136 estuaries as well as the open coast (Ogden, 1941).

137 Starting in the 1970s, descendants of the Big Sur sea otters began to appear in central

138 California estuaries (Fig. 1A; Lubina and Levin, 1988), and by the 1990s, they were common in

139 one estuary, Elkhorn Slough (Feinholz, 1998). The current southern sea otter recovery plan does

140 not include estuaries as target habitats (U.S. Fish and Wildlife Service, 2003), although estuaries

141 may represent a key component of continued southern sea otter recovery, and this had been 
142 recognized by recent status reports (U.S. Fish and Wildlife Service, 2015). The benefits of

143 estuarine habitats for sea otters that have been documented for Elkhorn Slough, such as low

144 predation risk (i.e., lack of predators like white sharks). Along the northern and southern limits

145 of the current range, non-consumptive bites by white sharks (Carcharodon carcharias) are the

146 greatest cause of mortality and a primary factor limiting continued expansion into adjacent areas

147 with a higher per-capita abundance of prey (Tinker et al., 2015).

148 Other benefits of estuaries for sea otters include ample prey (Hughes et al., 2013), haul

149 out opportunities (Eby et al., 2017), and sheltered nursery habitat. Sea otters in Elkhorn Slough

150 haul out extensively on salt marshes, even during daylight, and spend much more time hauled

151 out than do sea otters that have been studied along the open coast (Eby et al., 2017). Hauling out

152 may be more common in estuaries due to the availability of easily accessible, low relief habitat,

153 lower disturbance by humans than on coastal beaches, and high densities of sea otters, allowing

154 for group vigilance to potential predators (Eby et al., 2017). Hauling out can provide important

155 energetic benefits for sea otters, which unlike other marine mammals, have no blubber

156 insulation, an exceptionally high metabolic rate, and exhibit high thermal lability in sea water

157 (Costa \& Kooyman, 1982). The energetic benefits of hauling out may be especially important for

158 females with pups, as these animals incur the increased energy demands of lactation and pup-

159 rearing (Thometz et al., 2014). These benefits will likely be provided by other California

160 estuaries as they are recolonized by sea otters in the future. Moreover, the extensive shallow,

161 productive estuarine habitats may allow for accelerated population growth at the regional scale.

162 Virtually all findings on sea otters' top-down effects on coastal food webs, as well as our

163 understanding of the challenges to their recovery, were developed from open coast studies (Estes

164 \& Palmisano, 1974; Estes et al., 1998; Estes \& Hatfield, 2003). Nevertheless, recent studies 
165 (Hughes et al., 2013, 2016; Hessing-Lewis et al., 2017) suggest that sea otters can generate a

166 trophic cascade in estuarine ecosystems, albeit via different pathways than on the open coast.

167 Given the relatively recent recolonization of estuarine habitats and new insights from recent and

168 ongoing research (Hughes et al., 2013, 2016; Hessing-Lewis et al., 2017), it is timely to

169 synthesize the state of our understanding of the relationship between sea otters and estuaries, past

170 and present, and to consider the southern sea otter's recovery and restoration potential in

171 estuarine habitats within the subspecies' historic range.

172 Here we use multiple lines of inquiry to assess the potential role of estuaries for

173 supporting sea otter recovery. First, we explore the current scientific literature (post 1950) to

174 better understand how research effort on sea otters compares in different coastal ecosystems.

175 Next, we use a state-space model to estimate the processes of density-dependent population

176 growth for sea otters in one estuarine system (Elkhorn Slough) where sea otters have fully

177 recovered, and we apply this model to another large estuary (San Francisco Bay) outside the

178 current range of sea otters, to evaluate its potential to support sea otters. Finally, we surveyed

179 prey data from estuaries within and immediately outside the current sea otter range to determine

180 if there is adequate prey availability to support sea otter populations in estuaries outside the

181 current sea otter range.

182

183 Materials \& Methods

184 Historical research effort on estuaries as sea otter habitat

185 We summarized research efforts in different ecosystems using a Web of Science search

186 with the following terms: TOPIC: (sea otter*) AND TOPIC: (marsh* or salt marsh* or kelp* or

187 seagrass* or rocky* or soft-bottom* or nearshore* or coast* or subtidal* or intertidal* or beach* 
188 or embayment* or * bay* or shore*). Results were accessed on March 3, 2017. We divided

189 studies by two categories: 1) northern (Enhydra lutris kenyoni) and southern (E. lutris nereis) sea

190 otter populations, and 2) coastal ecosystem type (Open coast, estuary/embayment, and both). We

191 further subdivided population and coastal ecosystem type into habitats within the two ecosystems

192 (beach, kelp, rocky intertidal, seagrass, soft-bottom, and multiple).

193

194

195

196

197

198

199

200

201

202

203

204

205

206

207

208 211 (Tinker \& Hatfield, 2018) and are also provided in Dataset S1.

\section{State-space model of sea otter growth and equilibrium abundance in a California Estuary}

At the present time Elkhorn Slough is the only estuary in California in which a distinct and self-sustaining population of sea otters has become established (Kvitek et al., 1988; Maldini et al., 2012; Hughes et al., 2013; Eby et al., 2017), although with continued range expansion it is likely that other estuaries (including San Francisco Bay) will eventually be colonized given the current population is $<40 \mathrm{~km}$ away from the mouth of San Francisco Bay (Tinker \& Hatfield, 2017). Sea otters initially moved into the Slough in 1984 , however the early colonizers were mostly or entirely males (consistent with typical patterns of sea otter range expansion; Lafferty and Tinker 2014). Reproductive females did not become established in Elkhorn Slough until the early 2000s, largely as a result of the addition of re-habilitated juvenile female otters by the Monterey Bay Aquarium (Mayer et al., 2019), after which intrinsic growth of the Elkhorn Slough population was rapid (Estes \& Tinker, 2017). It is therefore reasonable to characterize the first 15 years of sea otter occupation in Elkhorn Slough as a population establishment phase, and we use data on population trends from 2000-2018 to assess the potential for growth and equilibrium of established populations in estuarine habitats. Annual survey data for Elkhorn Slough were extracted from USGS population survey data available in an online repository 
213 Bayesian state space model (SSM) to the time series of survey data for Elkhorn Slough using

214 established methods (Stroud, Muller \& Sanso, 2001). The rationale of an SSM is as follows: a

215 process model of population dynamics (in this case, a stochastic logistic growth model of

216 density-dependent population growth) is fit to a time series of population counts using Markov

217 Chain Monte Carlo methods. This method enables disentanglement of process error (i.e.

218 environmental stochasticity, the unexplained but real variation in annual growth rate, or $\lambda$ ) from

219 observer error (i.e. measurement and sampling error, the unexplained year-to-year differences in

220 sightability that do not reflect true abundance). We assume that true abundance, $N_{t}$, is a latent

221 variable whose dynamics are described as:

$$
N_{t}=N_{t-1} \cdot \exp \left(r\left[1-N_{t-1} / K\right]+\varepsilon_{t}\right), \quad \varepsilon_{t} \sim \mathrm{N}\left(0, \sigma_{p}\right)
$$

223

224

225

226

227

228

229

230

231

232

233

In equation $1, r$ is the intrinsic rate of population growth, $K$ is the equilibrium abundance, or carrying capacity, and $\mathrm{N}\left(0, \sigma_{p}\right)$ represents a random normal variable with mean 0 and standard deviation $\sigma_{p}$, a fitted parameter representing process error or environmental stochasticity. We note that equation 1 reflects simple logistic growth, a special case of theta-logistic growth where the implied value of theta (a parameter determining the shape of the relationship between $\log (\lambda)$ and density) is set to 1 . The assumption of simple logistic growth is recommended for data sets where there are insufficient data to reliably estimate theta (Clark et al., 2010) and is consistent with other simple models of sea otter population growth (Tinker, 2015; Tinker et al., 2019). In addition to obtaining estimates of $r$ and $K$ appropriate for estuarine habitats, we also derive estimates of equilibrium densities specific to habitat types, $K^{d}{ }_{h}$. We define three general habitat types for sea otters in Elkhorn Slough: 1) nearshore open water, 2) eelgrass beds, and 3) 
234 saltmarsh habitats (including both tidal creeks and adjacent pickleweed beds). To calculate $K^{d}$,

235 we define $A_{h}$ as the area of habitat type $h$ available in the Slough (in units of $\mathrm{km}^{2}$ ) and $p_{h}$ as the

236 proportion of all surveyed sea otters occurring in each habitat type $h$. We then calculate the

237 equilibrium densities for each habitat type as:

238

$$
K_{h}^{d}=\frac{p_{h} \cdot K}{A_{h}}
$$

To fit the process model defined by equation 1 , we relate the latent variable, $N_{t}$, to the negative binomial distribution with mean $N_{t}$ and variance $\sigma_{o}^{2}$ :

$$
C_{t} \sim N B(a, b), \quad a=N_{t}^{2} /\left(\sigma_{o}^{2}-N_{t}\right), \quad b=1-\left(\sigma_{o}^{2}-N_{t}\right) / \sigma_{o}^{2}
$$

243

244 252 degree. counts will, on average, be centered around true abundance, and thus does not account for imperfect detection. We recognize this is unrealistic, as some (small) proportion of animals are invariably missed on visual surveys (Estes \& Jameson, 1988); however, the un-replicated complete count method used to census otters in California does not provide a means of estimating a sightability correction factor. Consequently, for consistency with previous analyses of these survey data (e.g., Lubina \& Levin, 1988; Tinker et al., 2006; Lafferty \& Tinker, 2014), we make the simplifying assumption that counts are centered around true abundance, recognizing that this means that our estimates of $N_{t}$ are biased low to a small (but unmeasured)

We estimated parameters in equations 1-3 using Bayesian Markov Chain Monte Carlo methods (MCMC), implemented using JAGS ("Just Another Gibbs Sampler", Code S1) and the R programming language (Plummer, 2003; R Development Core Team, 2015). We used vague 
256 half-Cauchy priors for $K, N_{l}$ and all variance parameters, and an informative normal prior for $r$

257 with mean 0.2 and standard deviation 0.1 , based on the results of numerous studies showing that

$258 r_{\max }$ in recently established populations is consistently within the range 0.20-0.25 (Estes, 1990;

259 Gerber et al., 2004; Lafferty \& Tinker, 2014; Tinker, 2015; Tinker et al., 2019). After model

260 burn-in of 10000 simulations we saved 500 samples for each of 20 chains, for a total of 10000

261 samples used to calculate posterior distributions for all parameters and for the latent variable $N_{t}$

262 (Fig. S1). Model convergence was evaluated by graphical examination of the CODA traces, and

263 by ensuring that the $\mathrm{R}$-hat statistic $<1.01$ for all parameters. We also conduct posterior predictive

264 checking (PPC; Gelman et al., 2000) creating a scatter plot of a discrepancy measure (summed

265 deviance of observed counts) for replicate (simulated) versus actual (observed) data and

266 reporting the associated Bayesian-P value (requiring $0.25<\mathrm{P}<0.75$; Gelman et al., 2014). We then

267 summarize the mean, median, and 95\% credible intervals (CI) for the posterior distributions of 268 each parameter.

269

270

Applying State Space Model results to San Francisco Bay

271 We conservatively took the lower bound of the $95 \%$ CI of $K^{d}{ }_{h}$ for Elkhorn Slough

272 habitats as our point estimates for equilibrium densities of the equivalent habitats in the San

273 Francisco Bay estuary. A fourth habitat type, offshore open water (defined as areas $>2000 \mathrm{~m}$

274 from shore but still within the $40 \mathrm{~m}$ depth zone), occurred in San Francisco Bay but not in

275 Elkhorn Slough. Based on extensive data on the depths of sea otter foraging dives (Bodkin,

276 Esslinger \& Monson, 2004; Tinker et al., 2007; Thometz et al., 2016), individual habitat use data

277 from Washington (Laidre et al., 2009) and California (Tinker et al., 2017), and survey data from

278 large embayments in Alaska such as Prince William Sound, Yakutat Bay and Glacier Bay 
279 (Esslinger \& Bodkin, 2009; Esslinger et al., 2015; Tinker et al., 2019), it is clear that sea otters

280 utilize such offshore habitats, but that the densities of animals in offshore areas are substantially

281 lower than densities in the nearshore zone. For example, using published census data for

282 southern sea otters from 1985-2018 (Tinker \& Hatfield, 2018), and restricting analysis to areas of

283 soft sediment habitat along the open coast, we calculated that the number of otters observed

$284>2000 \mathrm{~m}$ from shore was just $15 \%$ of the number counted $<=2000 \mathrm{~m}$ from shore. To obtain an

285 estimate of equilibrium density for offshore areas $<40 \mathrm{~m}$ depth in San Francisco Bay $\left(K^{d}{ }_{4}\right)$, we

286 multiplied the equilibrium density for nearshore open water $\left(K^{d}\right)$ by a correction factor, $\Phi=0.1$,

287 thus conservatively assuming that offshore densities would be $\sim 10 \%$ of nearshore densities. We

288 used multiple GIS sources to characterize the four different sea otter habitats in San Francisco

289 Bay, including EcoAtlas (ecoatlas.org), the California Aquatic Resources Inventory (CARI) for

290 wetland habitats, and the Eelgrass Aquatic Resources for eelgrass habitats.

291 We applied our conservative estimates of habitat-specific equilibrium densities derived

292 from Elkhorn Slough to GIS layers of habitat cover in San Francisco Bay, then summed across

293 habitats to obtain a total estimated abundance at $K$ for San Francisco Bay (Table 1). We used this

294 value of $K$, together with parameter values for $r$ and of $\sigma_{p}$ estimated from Elkhorn Slough, to

295 parameterize 500000 forward simulations of population growth in San Francisco Bay (achieved

296 by iteratively solving equation 1 ). We draw all parameter values from their respective posterior

297 distributions, to account for parameter uncertainty. For all simulations we initialized the

298 population $\left(N_{I}\right)$ with 20 otters: assuming a female:male ratio of $2: 1$, this corresponds

299 (approximately) to the 14 rehabilitated juvenile female otters successfully introduced to Elkhorn

300 Slough between 2002 and 2014, and which contributed the majority of population growth during

301 this period (Mayer et al., 2019). We also assumed there would be a population establishment 
302 phase similar to that seen for Elkhorn Slough, we forced the mean growth rate to 0 for the first

30315 years. We summarize results of these simulations by plotting the mean expected trajectory

304 and $90 \%$ CI for 50 years of population dynamics. Finally, we examined the sensitivity of the

305 simulation results to our various assumptions and input parameters. Specifically, we sequentially

306 reduced each model parameter $\left(K_{h}^{d}, \Phi, r\right.$ and $\left.\sigma_{p}\right)$ by $10 \%$ of its default value, while holding other

307 parameters constant, and measured the proportional response in $N^{\prime}{ }_{50}$, the mean projected

308 abundance of the population after 50 years.

309

310

Prey availability in estuaries outside the sea otter range

311

To evaluate prey availability at sites within (Elkhorn Slough and Morro Bay) and outside

312 the current sea otter range (San Francisco Bay and Drakes Estero; Fig. 1A) we took two

313 approaches: first, we assembled existing prey species lists (excluding Drakes Estero); and

314 second, we sampled each estuary for crab, which have been documented to be important prey for

315 successful sea otter recolonization in estuaries (Garshelis \& Garshelis, 1984; Hughes et al.,

316 2013). To generate prey species lists we assembled data from various monitoring programs (see

317 Dataset S3 for references) that have sampled benthic prey in each estuary, and also include sea

318 otter prey surveys for two estuaries: Elkhorn Slough and Morro Bay.

319 To sample crab at each estuary we used standardized trapping techniques during summer

3202016 (Elkhorn Slough), fall 2016 (Drakes Estero, San Francisco Bay) and winter 2017 (Morro

321 Bay), (California Department of Fish and Wildlife, Permit SC-6563). Due to logistical feasibility

322 we were unable to sample all four sites within the same season. We used shrimp pots

323 (http://www.westmarine.com - Willapa Shrimp Pots) with modified openings that allow access

324 to large crabs yet still prevent access or entrapment of any larger predators, such as sea otters, 
325 birds, and harbor seals. The dimensions of the shrimp pots are $61 \mathrm{~cm} \times 61 \mathrm{~cm} \times 23 \mathrm{~cm}$, with four

326 openings that were rigidly supported and $\sim 20 \mathrm{~cm}$ in diameter. Each site had 7-8 locations

327 sampled over a single tidal cycle in Zostera marina seagrass beds, with the exception of Elkhorn

328 Slough which had four locations that were sampled multiple times $(\mathrm{n}=8-12$ times during

329 summer 2016). Each site received one trap per sampling effort, and traps were soaked for $\sim 24 \mathrm{hr}$,

330 afterward each crab was identified and measured for carapace width, which were converted to

331 edible biomass using linear functions from Oftedal et al. (2007). San Francisco Bay crab catch

332 per unit effort (CPUE) included the invasive European green crab (Carcinus maenas) caught in

333 an April 2017 crab survey, which we have observed to be a prey item of sea otters in Elkhorn

334 Slough (B. Hughes, pers. obs., 2015), but was not included in the biomass conversion estimates

335 in Oftedal et al. (2007). We applied a conservative biomass estimate for green crab using the

336 biomass conversion for C. magister. We consider this estimate conservative since green crab

337 have a relatively narrower carapace width relative to biomass.

338 To determine differences in crab prey availability in estuaries within and immediately

339 outside the southern sea otter range we compared differences in edible crab biomass and

340 carapace width of two common estuarine crab prey species: Romaleon antennarium and $C$.

341 productus. For one site, Elkhorn Slough, we used a historic dataset that surveyed crab in the

342 1970s (1971-1976, see Hughes et al. 2013 for a description of the data), to compare to the

343 contemporary crab trapping efforts at Elkhorn Slough and the other three estuaries. The 1970s

344 Elkhorn Slough crab dataset characterized Elkhorn Slough crab populations prior to sea otter

345 recolonization in the early 1980s, and thus helped support our interpretation of differences in

346 crab populations for our 2017 surveys.

347 Differences in sea otter presence (fixed factor) and site (random factor) of CPUE and size 
348 were determined using linear mixed models with the nlme package in R v. 3.4.3. A Tukey

349 multiple comparison test was used to compare differences among sites with and without sea 350 otters using the multcomp package.

351

\section{Results}

353 Historical research effort on estuaries as sea otter habitat

354 While many studies continue to be published on outer coast sea otters, our Web of

355 Science search resulted in few investigations examining estuarine sea otters (Fig. 1B, Dataset S1,

356 Code S2), and most of the estuarine studies are based on northern sea otters (Enhydra lutris

357 kenyoni), as we found only nine studies that focused specifically on estuarine ecosystems for

358 southern sea otters. Of all of the studies we examined $(n=158)$, only two focused on seagrass

359 (Zostera marina) habitats (Fig. 1C), and only one to our knowledge has focused on salt marshes

360 (Eby et al., 2017). Whereas, kelp was the most dominant single habitat for both northern and 361 southern sea otter populations.

362

363 State-space model of sea otter growth and equilibrium

364 The state-space model fit to survey data from Elkhorn Slough (Dataset S2, Code S3)

365 converged well and provided excellent fit to the data (Fig. S1). Trace plots of posterior samples

366 showed well-mixed chains (Figs. S2 and S3), with all R-hat statistics $<1.01$ (Table 1), and the

367 PPC scatterplot showed excellent agreement between replicate and observed data sets (Bayesian-

$368 \mathrm{P}=0.55$; Fig. S4). The estimated instantaneous rate of growth at low density $(r)$ was $0.22\left(\mathrm{CI}_{95}=\right.$

$3690.10-0.33)$, while the estimated magnitude of environmental stochasticity $\left(\sigma_{p}\right)$ was $0.30\left(\mathrm{CI}_{95}=\right.$

$3700.16-0.47)$. The estimated value of $K$ for Elkhorn Slough was $160\left(\mathrm{CI}_{95}=49-367\right)$, and using 
371 the lower bound of the $95 \%$ CI for $K$ we estimate habitat-specific equilibrium densities $\left(K_{h}^{d}\right)$ for

372 three habitat types: nearshore open water $\left(8.9\right.$ otters $\left.* \mathrm{~km}^{-2}\right)$, eelgrass beds $\left(19.2\right.$ otters $\left.* \mathrm{~km}^{-2}\right)$ and

373 saltmarsh habitats (4.5 otters* $\mathrm{km}^{-2}$; Table 1$)$.

374

375 Applying State Space Model results to San Francisco Bay

376 Our habitat-specific population growth model provides a conservative estimate for the 377 equilibrium abundance of sea otters in San Francisco Bay of over 6,600 animals (Table 1) and

378 shows that just 20 colonizers could grow to a population of 5000 or more within 50 years (Fig.

379 2C). There is a great deal of uncertainty in growth projections, evident in the wide CI bounds

380 around the mean projected trend in Fig 2C: this variability reflects both the effects of process

381 error (environmental stochasticity) and parameter uncertainty. To explore the latter source of

382 uncertainty we conducted a sensitivity analysis, the results of which indicated that the parameter

383 having the greatest impact on projected abundance was $r$, the rate of growth at low densities (Fig.

384 S5). The estimate of $K^{d}$ (equilibrium density in nearshore open water) had the next greatest

385 impact on $N^{\prime}{ }_{50}$, reflecting the predominance of this habitat type in San Francisco Bay. The

386 magnitude of environmental stochasticity $\left(\sigma_{p}\right)$ also had substantial influence, with a decrease in

$387 \sigma_{p}$ leading to an increase in projected abundance.

388 We note that our model projections are conservative in two respects: they assume lower

389 equilibrium densities than currently seen in Elkhorn Slough, and estimates of the distribution of a

390 key habitat type, eelgrass beds, are based on conservative estimates of the current distribution

391 and do not include positive feedback loops whereby sea otter recovery could promote further

392 seagrass expansion. Furthermore, we excluded certain estuarine habitats (beaches and subtidal

393 flats), which are also known to be used by sea otters (Kvitek et al., 1988), but for which reliable 
394 density estimates could not be obtained. Despite these caveats, our model results suggest that San

395 Francisco Bay could eventually support a sizeable southern sea otter population, 160\% or more

396 of the range-wide population as of 2018.

397

398

Prey availability in estuaries outside the sea otter range

Our comparison of prey availability in estuaries with sea otters (Elkhorn Slough and

Morro Bay) with one of the focal recovery sites - San Francisco Bay suggests that prey resources in San Francisco Bay are sufficient to sustain a healthy sea otter population. Out of the 52 prey species we identified in the two California estuaries with sea otters, $34(65 \%)$ occurred in San Francisco Bay (Table 2; Dataset S3). Prey species include some that are of value to commercial fisheries, such as Dungeness crab (Metacarcinus magister), littleneck clam (Leucoma staminea), and mussels (Mytilus spp.); and also include invasive species such as European green crab

\section{6 (Carcinus maenas).}

Crab survey efforts also indicate that our two focal sea otter recovery sites (San Francisco Bay and Drakes Estero) have an adequate supply of crab prey to support a sea otter population. Both estuaries had significantly greater crab biomass caught in standardized traps compared to the estuaries (Elkhorn Slough and Morro Bay) with sea otters (Fig. 3A), and Drakes Estero had a

411 significantly greater crab biomass than San Francisco Bay (Dataset S4, Code S4). When we

412 compared sizes, crabs (Romaleon antennarium and Cancer productus) from Drakes Estero were

413 significantly larger than crabs from San Francisco Bay (no sea otters) and the two sites with sea

414 otters (Fig. 3B, Dataset S5, Code S4). Furthermore, crabs of both species in Drakes Estero were

415 similar in size to Elkhorn Slough prior to sea otter recolonization in the 1970 s. Whereas, crab 
416 sizes in San Francisco Bay were intermediate, between Drakes Estero (no sea otters), Morro Bay

417 (with sea otters), and Elkhorn Slough (before and after sea otter recolonization).

418

419 Discussion

420

Paradise lost: sea otters in California estuaries

421

Despite a substantial increase in population size over the past century, southern sea otters

422 have recolonized only approximately 13\% of their historic range (U.S. Fish and Wildlife Service,

423 2015), and long-term population growth has been slow (3-5\% per year; Tinker \& Hatfield 2017)

424 compared to recovering populations of northern sea otters (E. l. kenyoni) (Estes, 1990), where

425 total population growth rates have been reported to be as high as $17-20 \%$ per year depending on

426 location. Although this discrepancy in population growth rates has been interpreted as evidence

427 of persistently high southern sea otter mortality, the observed population trajectory can largely be

428 explained as the combined effect of localized density-dependence and the strong spatial

429 structuring typical of sea otter populations. Adult females, in particular, rarely move more than

$43015 \mathrm{~km}$ per year from their home range center (Tinker, Doak \& Estes, 2008; Tarjan \& Tinker,

431 2016) along the predominantly long, narrow configuration of central California coastal habitat

432 (Tinker, 2015). In such elongated and essentially one-dimensional habitats, a large proportion of

433 the population occurs in resource-limited areas, with population growth and range expansion

434 occurring only at the extreme ends of the range (Bodkin, 2015; Tinker, 2015). In more complex,

435 multi-dimensional habitats (such as those occurring in southeast Alaska) there are typically

436 multiple expansion fronts; therefore, a greater proportion of the population occurs at sub-

437 equilibrium densities, resulting in faster growth rates at the regional scale. Because they afford a 
438 diversity of habitats and prey for range expansion, estuaries are among the ecosystems that are

439 expected to be conducive to rapid sea otter population growth.

440 Two estuaries are located within the current range of the southern sea otter: Elkhorn

441 Slough and Morro Bay. These estuaries are located to the north and south, respectively, of the

442 central portion of the range, where recovering southern sea otters have resided the longest and

443 are at or near equilibrium densities (Tinker, Doak \& Estes, 2008; Thometz et al., 2016; Tinker et

444 al., 2017). Sea otters recolonized the outer portion of Morro Bay estuary in 1973 (Lubina \&

445 Levin 1988) and have recently increased dramatically in number in Morro Bay Harbor (Tinker \&

446 Hatfield, 2017), but they have not fully recolonized the inland portion of the estuary. In contrast,

447 sea otters in Elkhorn Slough utilize inland estuarine habitats extensively. Over the past two

448 decades, the Elkhorn Slough population has increased rapidly to more than 100 animals and has

449 only recently shown signs of reaching equilibrium (Silliman et al., 2018). The initiation of the

450 period of rapid growth in Elkhorn Slough can partly attributed to the addition of rehabilitated sea

451 otters from the Monterey Bay Aquarium, and specifically to 14 females that survived for $>1$ year

452 post release and were among the first animals to reproduce in the Slough (Mayer et al, in press).

453 Our initialization of San Francisco simulations with 20 animals was explicitly based on this

454 scenario, although natural colonization would of course be expected to produce similar results.

455 Although some sea otters still leave Elkhorn Slough occasionally to forage along the

456 outer coast, most appear to be entirely resident within the estuary, using different habitats for

457 feeding, resting and interacting. This recovery demonstrates that estuarine habitats and prey

458 resources can support a high-density, fully resident sea otter population. Estuaries such as

459 Elkhorn Slough are home to diverse and abundant invertebrate communities (Wasson et al.,

460 2002), and sea otter prey such as clams, crabs and worms can recruit and grow rapidly (Dataset 
461 S3). The high productivity of prey resources has supported decades of high foraging success of

462 the dense sea otter population (Hughes et al., 2013; Silliman et al., 2018).

463 The two major estuaries currently inhabited by sea otters (Elkhorn Slough and Morro

464 Bay), comprise 2400 ha of total habitat and $<50$ ha of eelgrass habitat as of 2014 (Hughes et al.,

465 2013; MBNEP, 2014; Hughes et al., 2016). However, if estuaries immediately outside (100 km

466 to the north or south) the current sea otter range are included, the total available estuarine habitat

467 is much greater (Fig. 1A). Considering only those estuaries with eelgrass habitat (Bernstein et al.,

468 2011), which could be a catalyst for sea otter colonization and is an indicator of good estuarine

469 water quality and rich invertebrate prey resources, we found 11 more estuaries with a total area

470 of 135,000 ha, which is a 56 -fold increase in available estuarine habitat. In comparison, the total

471 available outer coast habitat within the same region is 147,000 ha (Laidre, Jameson \& DeMaster,

472 2001). When comparing the coverage of the two dominant habitat-forming species within the sea

473 otter range - eelgrass in estuaries and kelp (e.g., Macrocystis pyrifera) on the outer coast - we

474 conservatively estimated there to be 1750 ha of eelgrass habitat within the projected range, and

475 most of the habitat is from the northern side of the otter range (see Bernstein et al. 2011),

476 compared to about 5700 ha of available kelp habitat along the outer coast

477 (https://earthworks.stanford.edu/catalog/stanford-nf191bc1535). Even using our most

478 conservative estimates, eelgrass alone could provide $23 \%$ of the total sea otter recovery habitat

479 over the next few decades within the $100 \mathrm{~km}$ projected stretch of mainland California. This

480 estimate does not take into account the other important estuarine habitats available or useable for

481 sea otters, such as salt marshes, tidal creeks, and mudflats (Kvitek et al., 1988; Eby et al., 2017),

482 which could greatly add to the total estimate of new sea otter habitat. Taken together, estuaries

483 could provide important recovery habitat for sea otters as they expand to the north and south, and 
484 serve as a refuge for them when outer coast conditions, like El Niño-driven storm and warming

485 events, are not favorable for the sea otter's primary kelp habitat (Dayton \& Tegner, 1984;

486 Edwards, 2004).

487 If sea otters recolonize the large estuaries on the California coast, such as San Francisco 488 Bay and Drakes Estero, or if rehabilitated otters were proactively introduced, the potential for 489 population growth is profound (Figure 2C). As of 2014, eelgrass beds in San Francisco Bay 490 cover about 1100 ha (Merkel and Associates, 2014), and as of 2005 Drakes Estero eelgrass 491 coverage is 300 ha (Brown \& Becker, 2007). Drakes Estero has a relatively pristine watershed 492 where eelgrass beds have been observed to be stable since a 2005 survey (B. Becker, pers. obs., 493 2019). San Francisco Bay's watershed is highly developed with extensive anthropogenic 494 impacts, including wetland conversion and loss (Gedan et al. 2009). However, the Bay still 495 supports many of the same habitats and prey resources utilized by southern sea otters in their 496 currently occupied range (Table 2; Fig. 2A).

497 Sea otters are a prime example of a keystone predator in kelp forests: by regulating 498 herbivorous urchins, sea otters increase the abundance and distribution of kelp (Estes \& 499 Palmisano, 1974; Estes et al., 1998). This well-established paradigm has recently been 500 complemented by the discovery that sea otters play an analogous role in estuaries by enhancing 501 the resilience of seagrass to anthropogenic nutrient inputs (Hughes et al., 2013, 2016). Through 502 their high consumption rates of crabs in Elkhorn Slough, sea otters indirectly benefit seagrasses 503 that are threatened by extreme nutrient loading and eutrophication (Hughes et al., 2011, 2013).

504 By consuming crabs, sea otters can generate a trophic cascade, whereby small grazers $(<5 \mathrm{~cm})$ 505 are released from predation by crabs, which enables them to consume shade-causing algal 506 epiphytes that grow on the leaves of eelgrass (Zostera marina) (Hughes et al., 2013, 2016). Prior 
507 to sea otter recolonization of the Elkhorn Slough estuary in 1984, eelgrass was nearly locally

508 extinct. Since the recolonization of sea otters in the last three decades, eelgrass has recovered and

509 expanded in area by $>600 \%$, and sea otter population growth positively correlates with eelgrass

510 recovery (Hughes et al., 2013). At least in this ecological context, sea otters are capable of

511 mediating the harmful effects of poor water quality on seagrasses without management

512 intervention.

513 Results showing positive effects of sea otters in estuaries have regional conservation

514 implications, as many estuaries toward the northern and southern limits of the current range of

515 sea otters are highly threatened by anthropogenic stressors (Greene et al., 2015; Hessing-Lewis

516 et al., 2017). Recently, severe recent losses of eelgrass to the south of Elkhorn Slough in Morro

517 Bay (>95\% since 2007; (MBNEP, 2014)) have been observed, with the exception of areas near

518 the mouth where sea otters permanently reside. A wide range of on-going human impacts to

519 eelgrass in the north in San Francisco Bay (Boyer \& Wyllie-Echeverria, 2010) have created the

520 impetus for large-scale restoration. Eelgrass-facilitating trophic interactions may be one

521 mechanism by which successful conservation and restoration outcomes are maximized.

522

523 An ecosystem-based management approach to decisions about estuarine restoration efforts

524 The restoration of estuaries has become a priority for land managers because of the

525 shoreline protection, flood management, water filtration, wildlife habitat, recreational and

526 educational opportunities, and other services that estuaries provide. San Francisco Bay,

527 designated an "estuary of national significance" under the Clean Water Act, received \$5.2

528 million in funding through the Environmental Protection Agency in 2017 for water protection

529 and restoration projects in the San Francisco Bay area. Within the San Francisco Bay, the Don 
530 Edwards San Francisco Bay National Wildlife Refuge is carrying out the largest wetlands

531 restoration project on the West Coast, the South Bay Salt Pond Restoration project, with the aim

532 of improving the physical, biological, and chemical health of the estuary, including restoring

533 habitat for birds, fish, benthic invertebrates, marine mammals, and plants, some of which are

534 threatened or endangered. Re-occupation by sea otters could assist restoration goals (San

535 Francisco Bay Subtidal Habitat Goals Report, 2010) by enhancing the resilience and functioning

536 of estuaries through indirect effects. Potential ecological effects of sea otter recovery extend

537 beyond the top-down impacts of sea otter trophic interactions on seagrass recovery (Hughes et al.

5382013 \& 2016); they also encompass the well-established ecosystem services supported by

539 seagrass systems (Waycott et al., 2009), including a growing recognition of seagrass as a sink for

540 atmospheric carbon (Fourqurean et al., 2012; Greiner et al., 2013). Additionally, sea otter

541 bioengineering effects may have positive feedbacks in soft sediment habitats. Sea otter

542 consumption of clams and subsequent shell deposition can provide hard substrate in an otherwise

543 soft sediment system (Kvitek \& Oliver, 1992), which could promote the settlement and sub-

544 surface growth of invertebrates and algae, altering community structure and increasing fish

545 habitat. Finally, the physical disturbance created when sea otters forage for invertebrates within

546 seagrass and other soft-bottom ecosystems (Kvitek et al., 1988) may have ecosystem feedbacks

547 on benthic communities (Kvitek \& Oliver, 1992) and ecosystem resiliency.

$548 \quad$ Based on previously reported rates of range expansion in southern sea otters (Lubina and

549 Levin, 1988; Tinker et al, 2008; Lafferty \& Tinker, 2014), sea otter recolonization of other

550 California estuaries would be expected to happen gradually over coming decades. However, as

551 mentioned above, white shark predation now increasingly curtails range expansion at both ends

552 of the range (Tinker et al 2015). In the absence of natural range expansion, an option to be 
553 considered is "facilitated range expansion," focusing on under-utilized habitats such as estuaries,

554 where shark predation is reduced. This could be accomplished by the release of sea otters into

555 San Francisco Bay, Drakes Estero or other California estuaries, as was done for Elkhorn Slough

556 (Mayer et al., in press).

557 Before such introductions occur, coastal managers and decision-makers would need to

558 weigh the trade-offs associated with the return of a keystone predator to the estuarine ecosystems

559 they once occupied. The strength of sea otters' ecosystem effects is a result of their high rates of

560 consumption of invertebrate prey. For example, estuaries with sea otters (Elkhorn Slough and

561 Morro Bay) have a significantly lower crab size and crab biomass for the two most abundant

562 species of cancrid crab prey in California estuaries (Romaleon antennarium and Cancer

563 productus) than estuaries without sea otters (San Francisco Bay and Drakes Estero; Fig. 3). Sea

564 otters are voracious predators, consuming $25 \%$ of their body weight per day in invertebrate prey

565 (Costa \& Kooyman, 1982). As such, they can have very strong effects on the their prey (Hughes

566 et al., 2013; Needles et al., 2015; Hughes et al., 2016), and have been documented to forage in a

567 range of estuarine habitats, from seagrass beds to salt marshes (Fig. 4), exploiting a wide range

568 of prey items, including crabs, clams, mussels, and worms (Table 2; Dataset S3).

569 While sea otters have diverse diets that include many non-commercial species, sea otter

570 recolonization could affect commercial and recreational fisheries through competition or indirect

571 effects. Sea otter predation can impact shellfish fisheries by reducing target species' abundance

572 and size (Garshelis \& Garshelis, 1984). In estuaries where oyster aquaculture is practiced, such

573 as Tomales Bay or Morro Bay, it is conceivable that sea otters could affect oyster production,

574 although no data are currently available to assess the likelihood of such interactions other than

575 recent observations of sea otters consuming farmed oysters in Kachemak Bay, AK (B. Weitzman 
576 - Gulf Watch Alaska, pers. comm., 2019). Whereas far fewer fisheries occur in California

577 estuaries than on the open coast, estuaries provide important nursery habitat for some

578 commercially exploited species. Sea otter effects on spawning adult Dungeness crab would

579 likely be largely negative, while effects on Pacific herring (Clupea pallasii) would likely be

580 positive through beneficial effects on eelgrass habitat. The magnitude of positive or negative

581 effects on commercial or recreational fisheries is highly contingent on the particular ecological

582 setting, the fisheries involved, the number of sea otters present, and other factors.

583 Despite the positive or negative effects of sea otters on fisheries, sea otter viewing has

584 high recreational value and some people value their intrinsic presence and would view

585 reintroduction favorably. Sea otters are immensely popular with the public, in aquaria worldwide

586 and in their natural habitats. Visitors to Elkhorn Slough cite otter-watching as the number one

587 reason to visit this coastal habitat (Kildow \& Pendleton, 2010), and in situ cameras

588 (www.elkhornslough.org/ottercam) showing real time footage of sea otters in the estuary receive

589 tens of thousands of unique views each year. If sea otters become common along the shores of

590 San Francisco Bay, millions of additional people would have the opportunity to observe and

591 enjoy sea otters in habitat they historically occupied, and ecotourism opportunities and revenues

592 would increase accordingly. Sea otters could also build support for ecosystem restoration of

593 degraded seagrass and salt marsh habitats within estuaries (Van Dyke \& Wasson, 2005; Hughes

594 et al., 2013; Wasson et al., 2017). The linkage of sea otters to seagrass and salt marsh health

595 could help motivate public support for conservation and restoration of the entire ecosystem.

596 While estuaries provide suitable habitat for sea otters, they also pose different threats to

597 sea otters than the open coast because of their proximity to areas of intensive human use.

598 Pollutant inputs from adjacent land use activities are often high, and pollutants can be 
599 concentrated in shallow estuarine waters with long residence times. For instance, extremely high

600 DDT levels were measured in male sea otters from Moss Landing at the mouth of the Elkhorn

601 Slough Estuary (Jessup et al., 2010), although these high contaminant loads have not been linked

602 to lower rates of survival. Sea otters at Elkhorn Slough are also affected by roads that disrupt the

603 connectivity of historic estuarine wetlands (Fig. 4C). At two sites near the mouth of the Elkhorn

604 Slough Estuary, sea otters routinely cross roads that bisect estuarine habitats; one sea otter was

605 killed after being hit by a car in 2016, leading to efforts to slow traffic and enhance driver

606 awareness in these areas. Depending on the size of the estuary, speeding boats and shipping

607 traffic may also pose a risk to sea otters, either through direct strikes or through the potential for

608 an oil or other chemical spill. Finally, repeated disturbance throughout the day caused by

609 kayakers or eco-tourism boats may deprive sea otters of needed rest, deplete their energy

610 reserves, and increase their vulnerability to other stressors (see https://www.seaottersavvy.org).

611 Elkhorn Slough provides a unique perspective when considering suitable estuarine

612 habitats for sea otters outside their range. However, unique challenges of human overlap in

613 estuaries depending on the region and the individual estuary. San Francisco Bay, for example,

614 has undergone dramatic physical and biological alterations as a result of human uses both past

615 and present (San Francisco Bay Subtidal Habitat Goals Report, 2010). The Bay hosts four major

616 shipping ports, two crude oil refineries, and a network of commuter ferries, in addition to many

617 recreational boaters and wind surfers. Sea otters in San Francisco Bay would be exposed to the

618 threat of injury from vessel traffic and could incur chronic fitness costs associated with repeated

619 disturbance or displacement from preferred habitat. Heavy metal and organochlorine

620 contaminants such as methylmercury, polychlorinated biphenyls (PCBs), and DDT persist in

621 high concentrations in San Francisco Bay (SFEI, 2017), and sea otters could be exposed to these 
622 chemical pollutants through consumption of contaminated invertebrate prey (Jessup et al. 2010).

623 Large oil spills, although infrequent, are a potentially devastating threat to sea otters. Two oil

624 refineries (Chevron and Phillips 66) operate on the Richmond waterfront of San Francisco Bay,

625 receiving shipments of crude oil via tankers. San Francisco Bay experienced a major oil spill

626 event in 2007 when the M/V Cosco Busan struck the Bay Bridge and spilled 53,569 gallons of

627 fuel oil into the bay. Other threats associated with this urbanized estuary include an influx in

628 bacterial disease associated with wastewater treatment plant discharges, entanglement in

629 recreational or commercial fishing gear, exposure to harmful algal toxins, and destruction of

630 foraging habitat and invertebrate prey by underwater dredging and sand mining operations.

631 If the reintroduction of sea otters to one or more estuaries were formally proposed, the

632 engagement of the public and stakeholders would be necessary to fully explore the implications,

633 including potential direct and indirect effects. Decision support tools and analyses that consider

634 the full spectrum of trade-offs should accompany and inform management decisions. Marine

635 spatial planning, a process that enables decision-making around conservation trade-offs, is one

636 such tool that can aid in the gathering and disseminating of information regarding the issues

637 surrounding sea otter reintroduction into estuaries. This process is especially useful when the

638 needs and values of stakeholders become incompatible with conservation objectives. In

639 Australia, Atwood et al. (2015) demonstrated the trade-offs between the recovery of shark

640 predators, the abundance of herbivore bioturbators, and the seagrass system's ability to store

641 carbon. Similarly, in the northeast Pacific, key trade-offs include the recovery of listed species

642 (sea otters), the abundance of their prey (including shellfish resources), and the ecosystem-level

643 effects of sea otter reintroduction. Some of these ecological effects, while complex and difficult

644 to monetize, may tip the balance between human values and top predator recovery that have 
645 historically pitted top predators versus their prey, and human harvest thereof. For example, the

646 reintroduction of grey wolves into Yellowstone National Park has resulted in ecosystem benefits,

647 such as increased woody vegetation and stream functioning, that could outweigh the costs (i.e.,

648 predation on livestock; Ripple et al. 2014). Comparison of estuaries occupied (Elkhorn Slough

649 and Morro Bay) and unoccupied (San Francisco Bay and Drakes Estero) by sea otters offer the

650 potential for valuable insight on socio-ecological effects of coastwide recovery. In order to

651 realize the prospects of healthy coastlines, including the ecological restoration of estuarine

652 systems such as seagrasses and salt marshes, differential human values and the ecological,

653 cultural and economic trade-offs of sea otter recovery are crucial to consider.

654

655 Conclusions

656 Our views of sea otter influences on coastal habitats and our understanding of the factors limiting

657 their recovery have been grounded in open coast ecology. For the California population, this was

658 the result of a historical accident: specifically, that the recovering population spread from a

659 remnant source population located on a remote stretch of rugged open coast. Recent sea otter

660 studies from estuarine ecosystems have broadened conceptions of what we previously thought of

661 as a kelp forest animal. Sea otters influence and are influenced by estuarine habitats in very

662 different ways than their counterparts on the open coast. To understand their ecology and to

663 support their recovery requires a paradigm shift in which we recognize and further explore the

664 unique relationship of estuaries and sea otters.

665

666 Acknowledgements 
667 This publication is dedicated to the memory of our co-author, Susan Williams, whose leadership

668 and creativity inspired this work. BBH was funded through the David H. Smith Research

669 Conservation Fellowship and Cedar Tree Foundation and the Rebecca and Steve Sooy

670 Fellowship in Marine Mammals. KW was supported by a grant from NOAA's Office for Coastal

671 Management to the Elkhorn Slough National Estuarine Research Reserve. MHL and ER were

672 supported by the Hakai Institute, which has facilitated coastwide collaborations on sea otter

673 recovery in coastal habitats. SLW was supported by the University of California's Agricultural

674 Experimental Station. Sarah Codde and Gabriela Reyes (NPS) assisted with crab surveys in

675 Drakes Estero. Jen Miller and Melissa Patten assisted KEB with crab surveys in San Francisco

676 Bay. Paul Engel and Carola DeRooy (NPS) located historic sea otter remains from Native

677 American middens near Drakes Estero. The findings in this article are those of the authors and

678 conclusions do not necessarily represent the views of the U.S. Fish and Wildlife Service.

\section{References}

681 Atwood TB, Connolly RM, Ritchie EG, Lovelock CE, Heithaus MR, Hays GC, Fourqurean JW, 682 Macreadie PI. 2015. Predators help protect carbon stocks in blue carbon ecosystems. Nature 683 Climate Change 5:1038-1045. DOI: 10.1038/NCLIMATE2763.

684 Bernstein B, Merkel K, Chesney B, Sutula M. 2011. Recommendations for a southern California 685 regional eelgrass monitoring program. Southern California Coastal Water Research Project $686 \quad 632: 45$

687 Bodkin JL. 2015. Historic and Contemporary Status of Sea Otters in the North Pacific. In:

688 Larson S, Vanblaricom GR, Bodkin JL eds. Sea Otter Conservation. Elsevier, 43-61. DOI:

$689 \quad 10.1016 /$ B978-0-12-801402-8.00003-2. 
690 Bodkin JL, Esslinger GG, Monson DH. 2004. Foraging depth of sea otters and implications to 691 coastal marine communities. Marine Mammal Science 20:305-321. DOI: 10.1111/j.1748692 7692.2004.tb01159.x.

693 Boyer KE, Wyllie-Echeverria S. 2010. Eelgrass conservation and restoration in San Francisco 694 Bay: opportunities and constraints. Final report for the San Francisco Bay Subtidal Habitat 695 Goals Project.

696 Broughton JM. 1999. Resource Depression and Intensification During the Late Holocene, San 697 Francisco Bay: Evidence from the Emeryville Shellmound Vertebrate Fauna. University of $698 \quad$ California Anthropological Records 32.

699 Brown D, Becker B. 2007. Drakes Estero eelgrass, oyster bag, and oyster rack assessment $700 \quad$ DRAFT Trip Report - 3/20/2007.

701 Bryant HC. 1915. Sea otters near Point Sur. California Department of Fish and Game 1:134$702 \quad 135$.

703 Clark F, Brook BW, Delean S, Reşit Akçakaya H, Bradshaw CJA. 2010. The theta-logistic is 704 unreliable for modelling most census data. Methods in Ecology and Evolution 1:253-262. 705 DOI: $10.1111 /$ j.2041-210x.2010.00029.x.

706 Costa DP, Kooyman GL. 1982. Oxygen consumption, thermoregulation, and the effect of fur 707 oiling and washing on the sea otter, Enhydra lutris. Canadian Journal of Zoology 60:2761$708 \quad 2767$. DOI: $10.1139 / \mathrm{z} 82-354$.

709 Dayton PK, Tegner MJ. 1984. Catastrophic storms, El Niño, and patch stability in a Southern $710 \quad$ California kelp community. Science 224:283-285.

711 Van Dyke E, Wasson K. 2005. Historical ecology of a central California estuary: 150 years of 712 habitat change. Estuaries 28:173-189. 
713 Eby R, Scoles R, Hughes BB, Wasson K. 2017. Serendipity in a salt marsh: detecting frequent

714 sea otter haul outs in a marsh ecosystem. Ecology in press. DOI: 10. 1002/ecy.1965.

715 Edwards MS. 2004. Estimating scale-dependency in disturbance impacts: El Niños and giant

716 kelp forests in the northeast Pacific. Oecologia 138:436-47. DOI: 10.1007/s00442-003-

$717 \quad 1452-8$

718 Esslinger GG, Bodkin JL. 2009. Status and trends of sea otter populations in Southeast

$719 \quad$ Alaska,1969-2003.

720 Esslinger G, Esler DN, Howlin S, Starcevich LA. 2015. Monitoring population status of sea

721 otters (Enhydra lutris) in Glacier Bay National Park and Preserve, Alaska: options and

722 considerations. Reston, VA.

723 Estes JA. 1990. Growth and equilibrium in sea otter populations. Journal of Animal Ecology

724 59:385-401. DOI: $10.2307 / 4870$.

725 Estes JA, Hatfield BB. 2003. Causes of mortality in California sea otters during periods of

726 population growth and decline. Marine Mammal Science 19:198-216. DOI: 10.1111/j.1748-

727 7692.2003.tb01102.x.

728 Estes JA, Jameson RJ. 1988. A Double-Survey Estimate for Sighting Probability of Sea Otters in

729 California. The Journal of Wildlife Management 52:70. DOI: 10.2307/3801061.

730 Estes JA, Palmisano JF. 1974. Sea otters: Their role in structuring shore communities. Science

$731 \quad 185: 1058-1060$.

732 Estes JA, Terborgh J, Brashares JS, Power ME, Berger J, Bond WJ, Carpenter SR, Essington TE,

733 Holt RD, Jackson JBC, Marquis RJ, Oksanen L, Oksanen T, Paine RT, Pikitch EK, Ripple

734 WJ, Sandin SA, Scheffer M, Schoener TW, Shurin JB, Sinclair ARE, Soulé ME, Virtanen

735 R, Wardle DA. 2011. Trophic downgrading of planet Earth. Science 333:301-6. 
736 Estes JA, Tinker MT. 2017. Rehabilitating sea otters: feeling good versus being effective. In:

737 Kareiva P, Marvier M, Silliman B eds. Effective Conservation Science: Data Not Dogma.

738 Oxford: Oxford University Press,.

739 Estes JA, Tinker MT, Williams TM, Doak DF. 1998. Killer whale predation on sea otters:

740 linking oceanic and nearshore ecosystems. Science 282:473-476. DOI:

$741 \quad 10.1126 /$ science.282.5388.473.

742 Feinholz DM. 1998. Abundance, distribution, and behavior of the southern sea otter (Enhydra

743 lutris nereis) in a California estuary. Aquatic Mammals 24:105-115.

744 Fourqurean JW, Duarte CM, Kennedy H, Marbà N, Holmer M, Mateo MA, Apostolaki ET,

745 Kendrick GA, Krause-Jensen D, McGlathery KJ, Serrano O. 2012. Seagrass ecosystems as

746 a globally significant carbon stock. Nature Geoscience 5:505-509. DOI: 10.1038/ngeo1477.

747 Garshelis DL, Garshelis JA. 1984. Management and movements of sea otters in Alaska. Journal

$748 \quad$ of Wildlife Management 48:665-678.

749 Gelman A, Carlin JB, Stern HS, Dunson DB, Vehtari A, Rubin DB. 2014. Bayesian Data

750 Analysis, Third Edition. DOI: 10.1007/s13398-014-0173-7.2.

751 Gelman A, Goegebeur Y, Tuerlinckx F, Van Mechelen I. 2000. Diagnostic checks for discrete

752 data regression models using posterior predictive simulations. Journal of the Royal

$753 \quad$ Statistical Society: Series C (Applied Statistics). DOI: 10.1111/1467-9876.00190.

754 Gerber LR, Tinker MT, Doak DF, Estes JA, Jessup DA. 2004. Mortality sensitivity in life-stage

755 simulation analysis: A case study of southern sea otters. Ecological Applications 14. DOI:

$756 \quad 10.1890 / 03-5006$.

757 Greene CM, Blackhart K, Nohner J, Candelmo A, Nelson DM. 2015. A national assessment of

758 stressors to estuarine fish habitats in the contiguous USA. Estuaries and Coasts 38:782- 
799. DOI: $10.1007 / \mathrm{s} 12237-014-9855-9$.

760 Greiner JT, McGlathery KJ, Gunnell J, McKee BA. 2013. Seagrass Restoration Enhances "Blue

761 Carbon" Sequestration in Coastal Waters. PLOS ONE 8:e72469. DOI:

$762 \quad$ 10.1371/journal.pone.0072469.

763 Hessing-Lewis M, Rechsteiner EU, Hughes BB, Tim Tinker M, Monteith ZL, Olson AM,

764 Henderson MM, Watson JC. 2017. Ecosystem features determine seagrass community

765 response to sea otter foraging. Marine Pollution Bulletin:1-11. DOI:

$766 \quad$ 10.1016/j.marpolbul.2017.09.047.

767 Hughes BB, Eby R, Van Dyke E, Tinker MT, Marks CI, Johnson KS, Wasson K. 2013.

768 Recovery of a top predator mediates negative eutrophic effects on seagrass. Proceedings of 769 the National Academy of Sciences of the United States of America 110:15313-15318.

770 Hughes BB, Hammerstrom KK, Grant NE, Hoshijima U, Eby R, Wasson K. 2016. Trophic

771 cascades on the edge: fostering seagrass resilience via a novel pathway. Oecologia $772 \quad 182: 231-241$.

773 Hughes BB, Haskins J, Wasson K, Watson E. 2011. Identifying factors that influence expression 774 of eutrophication in a central California estuary. Marine Ecology Progress Series 439:3177543.

776 Jackson JB, Kirby MX, Berger WH, Bjorndal KA, Botsford LW, Bourque BJ, Bradbury RH,

777 Cooke R, Erlandson J, Estes JA, Hughes TP, Kidwell S, Lange CB, Lenihan HS, Pandolfi

778 JM, Peterson CH, Steneck RS, Tegner MJ, Warner RR. 2001. Historical overfishing and the 779 recent collapse of coastal ecosystems. Science 293:629-637.

780 Jessup DA, Johnson CK, Estes J, Carlson-Bremer D, Jarman WM, Reese S, Dodd E, Tinker MT, 781 Ziccardi MH. 2010. Persistent organic pollutants in the blood of free-ranging sea otters 
782

783

784

785

786

787

788

789

790

791

792

793

794

795

796

797

798

799

800

801

802

803 804

(Enhydra lutris ssp.) in Alaska and California. Journal of Wildlife Diseases 46:1214-1233. DOI: $10.7589 / 0090-3558-46.4 .1214$.

Jones TL, Culleton BJ, Larson S, Mellinger S, Porcasi JF. 2011. Toward a prehistory of the southern sea otter (Enhydra lutris nereis). In: Human Impacts on Seals, Sea Lions, and Sea Otters: Integrating Archaeology and Ecology in the Northeast Pacific. The Regents of the University of California, 243-271.

Kildow J, Pendleton L. 2010. Elkhorn Slough restoration policy and economics report. Monterey, CA, USA.

Kvitek RG, Fukayama AK, Anderson BS, Grimm BK. 1988. Sea otter foraging on deepburrowing bivalves in a California coastal lagoon. Marine Biology 98:157-167. DOI:

10.1007/BF00391191.

Kvitek RG, Oliver JS. 1992. Influence of sea otters on soft-bottom prey communities in southeast Alaska. Marine Ecology Progress Series 82:103-113. DOI: 10.3354/meps082103.

Lafferty K, Tinker M. 2014. Sea otters are recolonizing southern California in fits and starts. Ecosphere 5:1-11.

Laidre KL, Jameson RJ, DeMaster DP. 2001. An estimation of carrying capacity for sea otters along the California coast. Marine Mammal Science 17:294-309. DOI: 10.1111/j.17487692.2001.tb01272.x.

Laidre KL, Jameson RJ, Gurarie E, Jeffries SJ, Allen H. 2009. Spatial Habitat Use Patterns of Sea Otters in Coastal Washington. Journal of Mammalogy 90:906-917. DOI: 10.1644/08MAMM-A-338.1.

Lowry LF, Pearse JS. 1973. Abalones and sea urchins in an area inhabited by sea otters. Marine Biology 23:213-219. 
805 Lubina JA, Levin SA. 1988. The spread of a reinvading species: range expansion in the

806 California sea otter. American Naturalist 131:526-543. DOI: 10.1086/284804.

807 Maldini D, Scoles R, Eby R, Cotter M, Rankin RW. 2012. Patterns of sea otter haul-out behavior

808 in a california tidal estuary in relation to environmental variables. Northwestern Naturalist 809 93:67-78. DOI: 10.1898/10-29.1.

810 Mayer KA, Tinker MT, Nicholson TE, Murray MJ, Johnson AB, DeAngelo C, Van Houtan KS.

811 2019. Surrogate rearing a keystone species to enhance population and ecosystem

812 restoration. Oryx in press.

813 MBNEP. 2014. State of the Bay: A report on the health of the Morro Bay Estuary. Morro Bay

$814 \quad$ National Estuary Program:24.

815 Merkel and Associates. 2014. San Francisco Bay Eelgrass Inventory. Prepared for the National 816 Marine Fisheries Service:72.

817 Needles LA, Gosnell JS, Waltz GT, Wendt DE, Gaines SD. 2015. Trophic cascades in an

818 invaded ecosystem: Native keystone predators facilitate a dominant invader in an estuarine 819 community. Oikos 124:1282-1292. DOI: 10.1111/oik.01865.

820 Oftedal OT, Ralls K, Tinker MT, Green A. 2007. Nutritional constraints in the southern sea 821 otter in the Monterey National Marine Sanctuary and a comparison to sea otter populations 822 at San Nicolas Island, California and Glacier Bay, Alaska. Joint Final Report to Monterey 823 Bay National Marine Sanctuary.

824 Ogden A. 1941. The California Sea Otter Trade, 1784-1848. Berkeley, CA: University of $825 \quad$ California Press.

826 Plummer M. 2003. JAGS: A program for analysis of Bayesian models using Gibbs sampling. 827 Proceedings of the 3rd International Workshop on Distributed Statistical Computing; 
Vienna, Austria.

829 R Development Core Team. 2015. R: A language and environment for statistical computing. R

830 Foundation for Statistical Computing, Vienna, Austria. URL http://www.R-project.org/. $R$

$831 \quad$ Foundation for Statistical Computing, Vienna, Austria.

832 Ripple WJ, Estes JA, Beschta RL, Wilmers CC, Ritchie EG, Hebblewhite M, Berger J,

833 Elmhagen B, Letnic M, Nelson MP, Schmitz OJ, Smith DW, Wallach AD, Wirsing AJ.

834 2014. Status and ecological effects of the world's largest carnivores. Science 343:1241484.

835 DOI: $10.1126 /$ science. 1241484.

836 San Francisco Bay Subtidal Habitat Goals Report. 2010. San Francisco Bay Subtidal Habitat

837 Goals Report: 50-Year Conservation Plan. San Francisco, CA.

838 Schenck WE. 1926. The Emeryville Shellmound, Final Report. University of California

$839 \quad$ Publications in American Archaeology and Ethnology 23:163.

840 SFEI. 2017. The Pulse of the Bay: The 25th Aniversery of the RMP. SFEI Contribution \#841.

$841 \quad$ Richmond, CA.

842 Silliman BR, Hughes BB, Gaskins LC, He Q, Tinker MT, Read A, Nifong J, Stepp R. 2018. Are

843 the ghosts of nature's past haunting ecology today? Current Biology 28:R532-R537. DOI:

$844 \quad$ 10.1016/j.cub.2018.04.002.

845 Simenstad CA, Estes JA, Kenyon KW. 1978. Aleuts, sea otters, and alternate stable-state

$846 \quad$ communities. Science 200:403-11. DOI: 10.1126/science.200.4340.403.

847 Stroud JR, Muller P, Sanso B. 2001. Dynamic models for spatiotemporal data. Journal of the

848 Royal Statistical Society. Series B (Statistical Methodology) 63:673-689. DOI:

$849 \quad 10.2307 / 2680659$.

850 Tarjan LM, Tinker MT. 2016. Permissible home range estimation (PHRE) in restricted habitats: 
851 A new algorithm and an evaluation for sea otters. PLoS ONE 11. DOI:

$852 \quad 10.1371 /$ journal.pone.0150547.

853 Thometz NM, Staedler MM, Tomoleoni JA, Bodkin JL, Bentall GB, Tinker MT. 2016. Trade-

854 offs between energy maximization and parental care in a central place forager, the sea otter.

855 Behavioral Ecology 27:1552-1566. DOI: 10.1093/beheco/arw089.

856 Thometz NM, Tinker MT, Staedler MM, Mayer KA, Williams TM. 2014. Energetic demands of

857 immature sea otters from birth to weaning: implications for maternal costs, reproductive

858 behavior and population-level trends. The Journal of Experimental Biology 217:2053-2061.

859 Tinker MT. 2015. The Use of Quantitative Models in Sea Otter Conservation. In: Larson S,

860 VanBlaricom G, Bodkin J eds. Sea Otter Conservation. New York: Elsevier, 257-300.

861 Tinker MT, Costa DP, Estes JA, Wieringa N. 2007. Individual dietary specialization and dive

862 behaviour in the California sea otter: Using archival time-depth data to detect alternative

863 foraging strategies. Deep Sea Research Part II: Topical Studies in Oceanography 54:330-

864 342. DOI: $10.1016 / j . d s r 2.2006 .11 .012$.

865 Tinker MT, Doak DF, Estes JA. 2008. Using demography and movement behavior to predict

866 range expansion of the Southern Sea Otter. Ecological Applications 18:1781-1794. DOI:

$867 \quad 10.1890 / 07-0735.1$.

868 Tinker MT, Doak DF, Estes JA, Hatfield BB, Staedler MM, Bodkin JL. 2006. Incorporating

869 diverse data and realistic complexity into demographic estimation procedures for sea otters.

$870 \quad$ Ecological Applications 16:2293-2312. DOI: 10.1890/1051-

$871 \quad$ 0761(2006)016[2293:IDDARC]2.0.CO;2.

872 Tinker MT, Gill VA, Esslinger GG, Bodkin J, Monk M, Mangel M, Monson DH, Raymond

873 WW, Kissling ML. 2019. Trends and Carrying Capacity of Sea Otters in Southeast Alaska. 
The Journal of Wildlife Management. DOI: 10.1002/jwmg.21685.

875 Tinker MT, Hatfield B. 2017. California Sea Otter (Enhydra lutris nereis) Census Results, $876 \quad$ Spring 2017. DOI: 10.3133/ds1018.

877 Tinker MT, Hatfield BB. 2018. Annual California sea otter census data. United States $878 \quad$ Geological Survey.

879 Tinker MT, Hatfield BB, Harris MD, Ames JA. 2015. Dramatic increase in sea otter mortality 880 from white sharks in California. Marine Mammal Science 32. DOI: 10.1111/mms.12261.

881 Tinker MT, Tomoleoni J, LaRoche N, Bowen L, Miles AK, Murray M, Staedler M, Randell Z. 882 2017. Southern sea otter range expansion and habitat use in the Santa Barbara Channel, 883 California. DOI: 10.3133/ofr20171001.

884 U.S. Fish and Wildlife Service. 2003. Final Revised Recovery Plan for the Southern Sea Otter 885 (Enhydra lutris nereis).

886 U.S. Fish and Wildlife Service. 2015. Southern sea otter (Enhydra lutris nereis) 5-year review: 887 summary and evaluation. Ventura, CA.

888 Wasson K, Jeppesen R, Endris C, Perry DC, Woolfolk A, Beheshti K, Rodriguez M, Eby R, 889 Watson EB, Rahman F, Haskins J, Hughes BB. 2017. Eutrophication decreases salt marsh 890 resilience through proliferation of algal mats. 212:1-11.

891 Wasson K, Nybakken J, Kvitek R, Braby C, Silberstein M. 2002. Invertebrates. In: Caffrey J, 892 Brown M, Tyler W, Silberstein M eds. Changes in a California Estuary: a Profile of 893 Elkhorn Slough. Moss Landing, CA: Elkhorn Slough Foundation, 135-161.

894 Waycott M, Duarte CM, Carruthers TJB, Orth RJ, Dennison WC, Olyarnik S, Calladine A, 895 Fourqurean JW, Heck KL, Hughes AR, Kendrick GA, Kenworthy WJ, Short FT, Williams 896 SL. 2009. Accelerating loss of seagrasses across the globe threatens coastal ecosystems. 
897 Proceedings of the National Academy of Sciences of the United States of America

$898 \quad 106: 12377-81$.

899 
Fig. Legends

903

904

905

906

907

908

909

910

Figure 1. Current status of sea otter distribution and research effort in different ecosystems

911

912 Figure 2. Sea otter habitat (A) and population growth model (B-C) for San Francisco Bay. (A)

913 Estuarine habitats in San Francisco Bay that correspond to habitats currently used by sea

914 otters in Elkhorn Slough, including saltmarsh with tidal creeks, open water, and eelgrass

915 (Zostera marina). (B) Expected distribution and projected density at $K$ of sea otters in San

916 Francisco Bay, computed by applying the lower 95\% CI of estimated carrying capacity for

917 the equivalent habitats in Elkhorn Slough (these densities correspond to approximately $38 \%$

918 of the current Elkhorn Slough density); C) Projected growth of a resident sea otter

919 population in San Francisco Bay over a 50 year period, initialized with 20 animals at year 1

920 and assuming similar dynamics as observed in Elkhorn Slough (but using conservative

921 estimates of carrying capacity). Grey band encompasses $90 \%$ of simulations.

922

923 Figure 3. Crab prey metrics in select California estuaries with and without sea otters: (A) Catch 
924 per unit effort (CPUE) caught in standardized crab traps over a 24 hour period, (B) mean

925 carapace width of two common crab prey species (Romaleon antennarium and Cancer

926 productus) in California estuaries, pre-otter Elkhorn Slough data are from Hughes et al.

927 (2013). Lowercase letters indicate significant differences $(\mathrm{P}<0.05)$ between estuaries based 928 on Tukey HSD tests.

929

930 Figure 4. Sea otters in estuarine and coastal habitats in Elkhorn Slough: A) resting in an eelgrass

931 bed (Zostera marina), B) hauled out on pickleweed marsh (Salicornia pacifica), C) a sea

932 otter crossing the road between salt marshes. Photo credits: A) Joseph Tomoleoni, B) Ron

933 Eby, C) Natsuko Fujimoto.

934 


\section{Figure 1}

Current status of sea otter distribution and research effort in different ecosystems and habitats.

(A) Range of southern sea otters in California estuaries as of 2018. Red points indicate estuaries where permanent populations currently exist. Blue and black points indicate estuaries within $100 \mathrm{~km}$ of the current range (indicated by the red line)(Tinker \& Hatfield, 2018), and blue and red sites are focal sites used in this study. (B-C) Literature search documenting ecosystem habitat use by sea otters for: (B) three coastal ecosystems, and (C) habitats within the three ecosystems. The Southern population (Enhydra lutris nereis) represents California (south of $40^{\circ} \mathrm{N}$ ), and the Northern population covers sea otters (E. lutris kenyoni) north of $40^{\circ} \mathrm{N}$. 

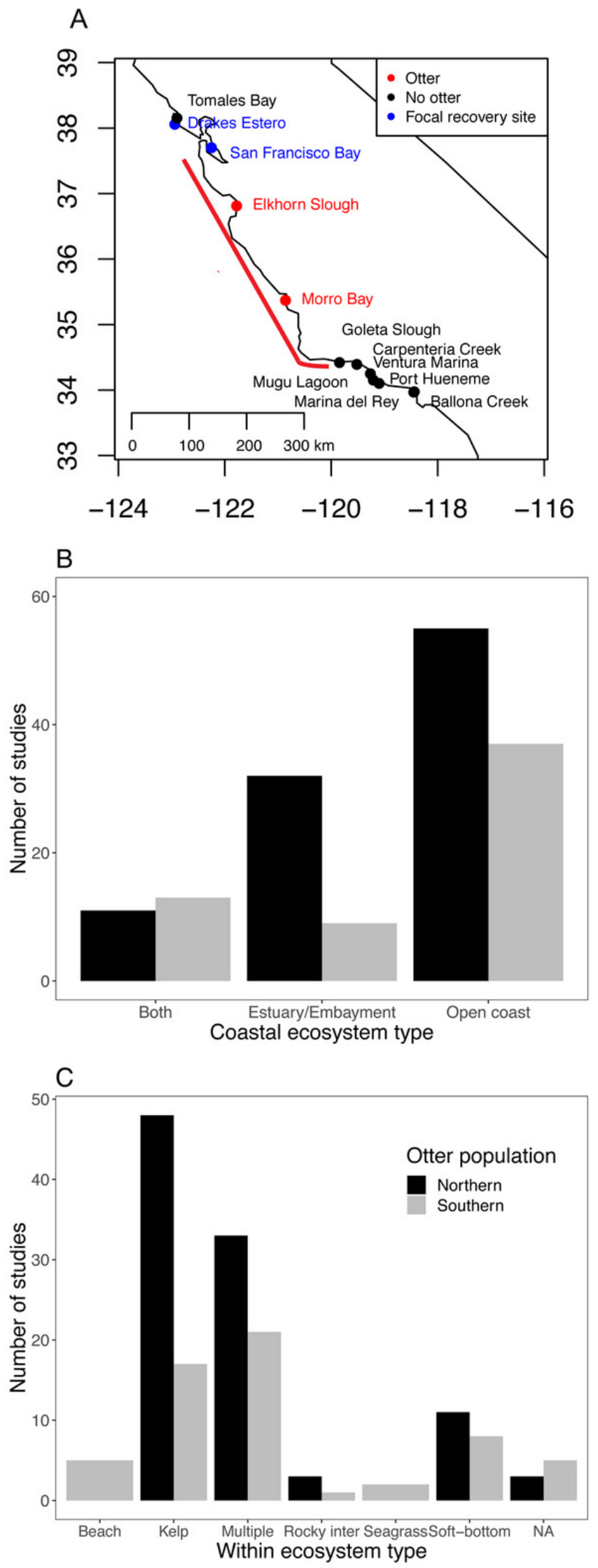


\section{Figure 2}

Sea otter habitats (A) and growth model for San Francisco Bay (B-C).

(A) Estuarine habitats in San Francisco Bay that correspond to habitats currently used by sea otters in Elkhorn Slough, including saltmarsh with tidal creeks, open water, and eelgrass (Zostera marina). (B) Expected distribution and projected density at Kof sea otters in San Francisco Bay, computed by applying the lower $95 \% \mathrm{Cl}$ of estimated carrying capacity for the equivalent habitats in Elkhorn Slough (these densities correspond to approximately $38 \%$ of the current Elkhorn Slough density); C) Projected growth of a resident sea otter population in San Francisco Bay over a 50 year period, initialized with 20 animals at year 1 and assuming similar dynamics as observed in Elkhorn Slough (but using conservative estimates of carrying capacity). Grey band encompasses $90 \%$ of simulations. 
A

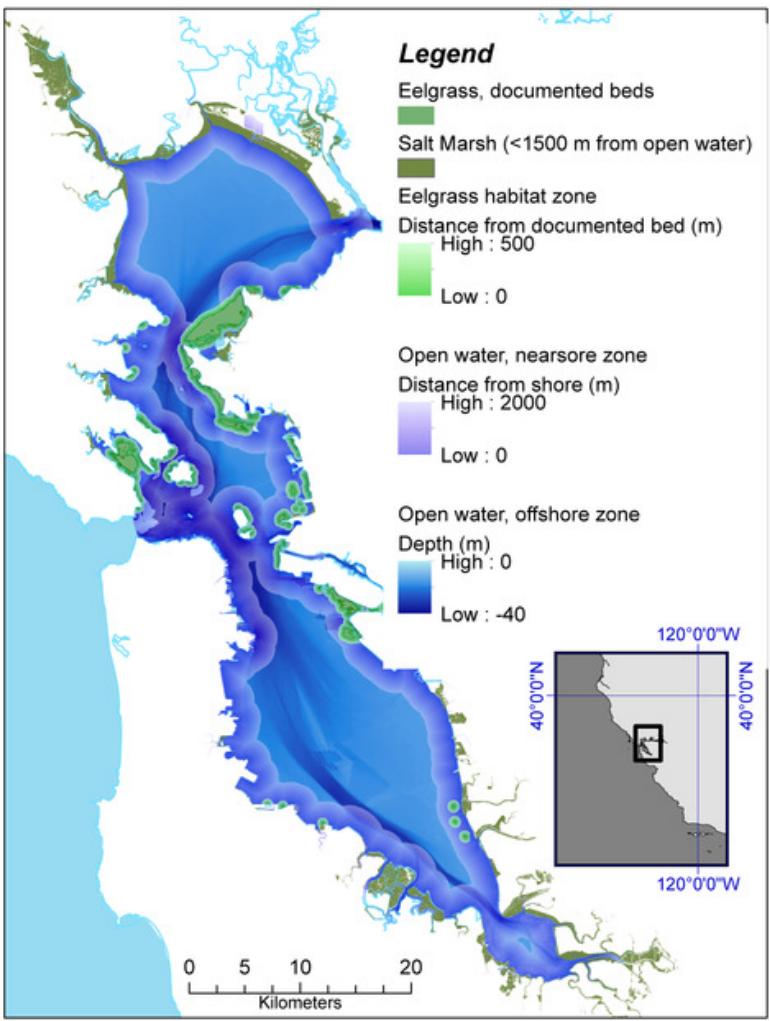

C

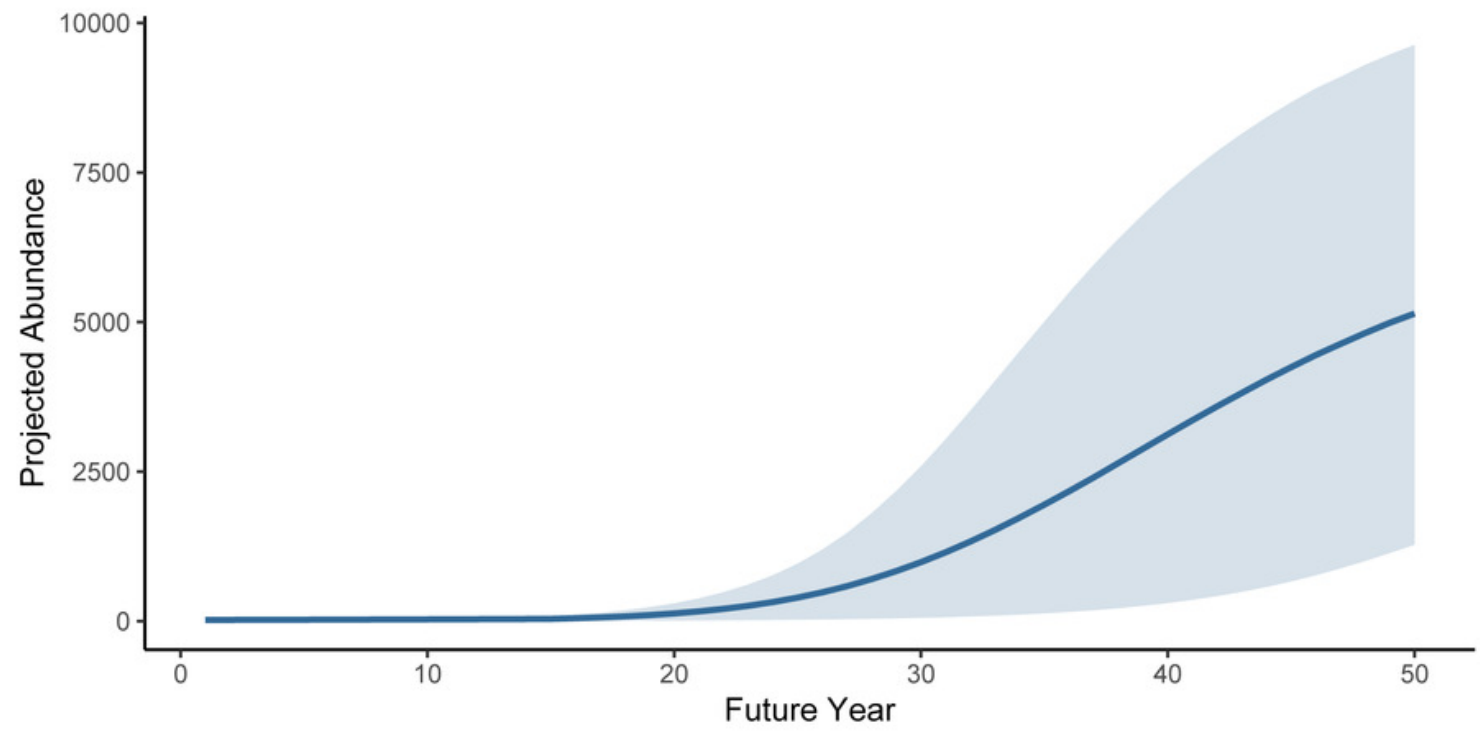

B

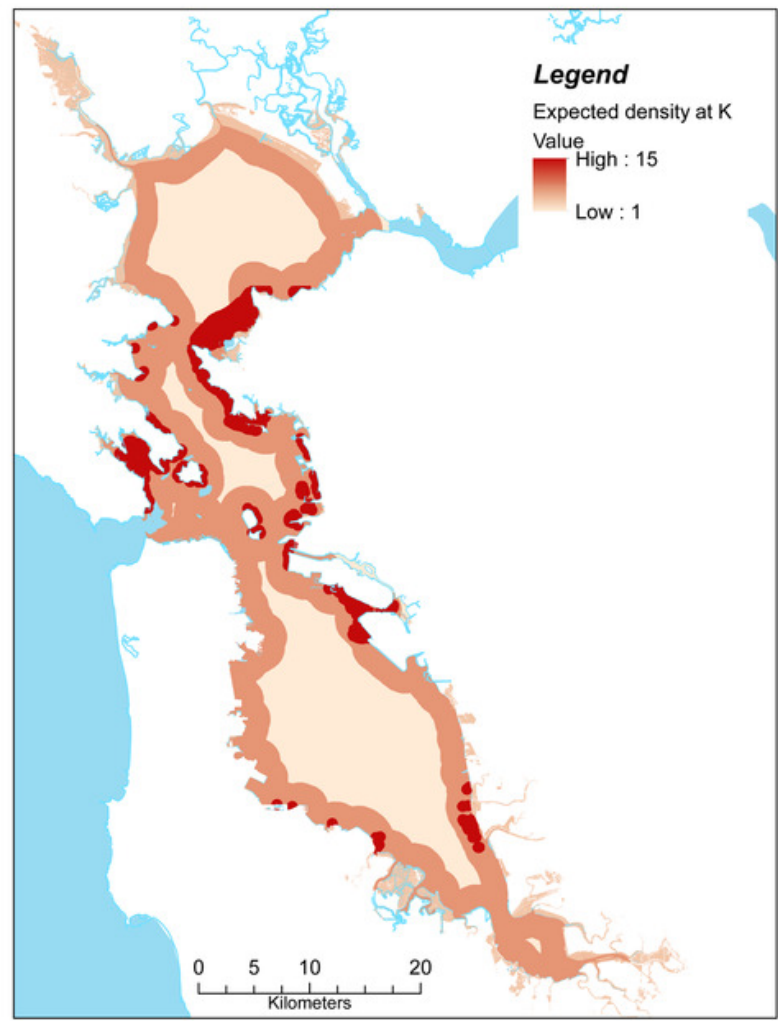

uture Year 


\section{Figure 3}

Crab prey metrics in select California estuaries with and without sea otters.

(A) Catch per unit effort (CPUE) caught in standardized crab traps over a 24 hour period, (B) mean carapace width of two common crab prey species (Romaleon antennariumand Cancer productus) in California estuaries, pre-otter Elkhorn Slough data are from Hughes et al. (2013).Lowercase letters indicate significant differences $(P<0.05)$ between estuaries based on Tukey HSD tests. 

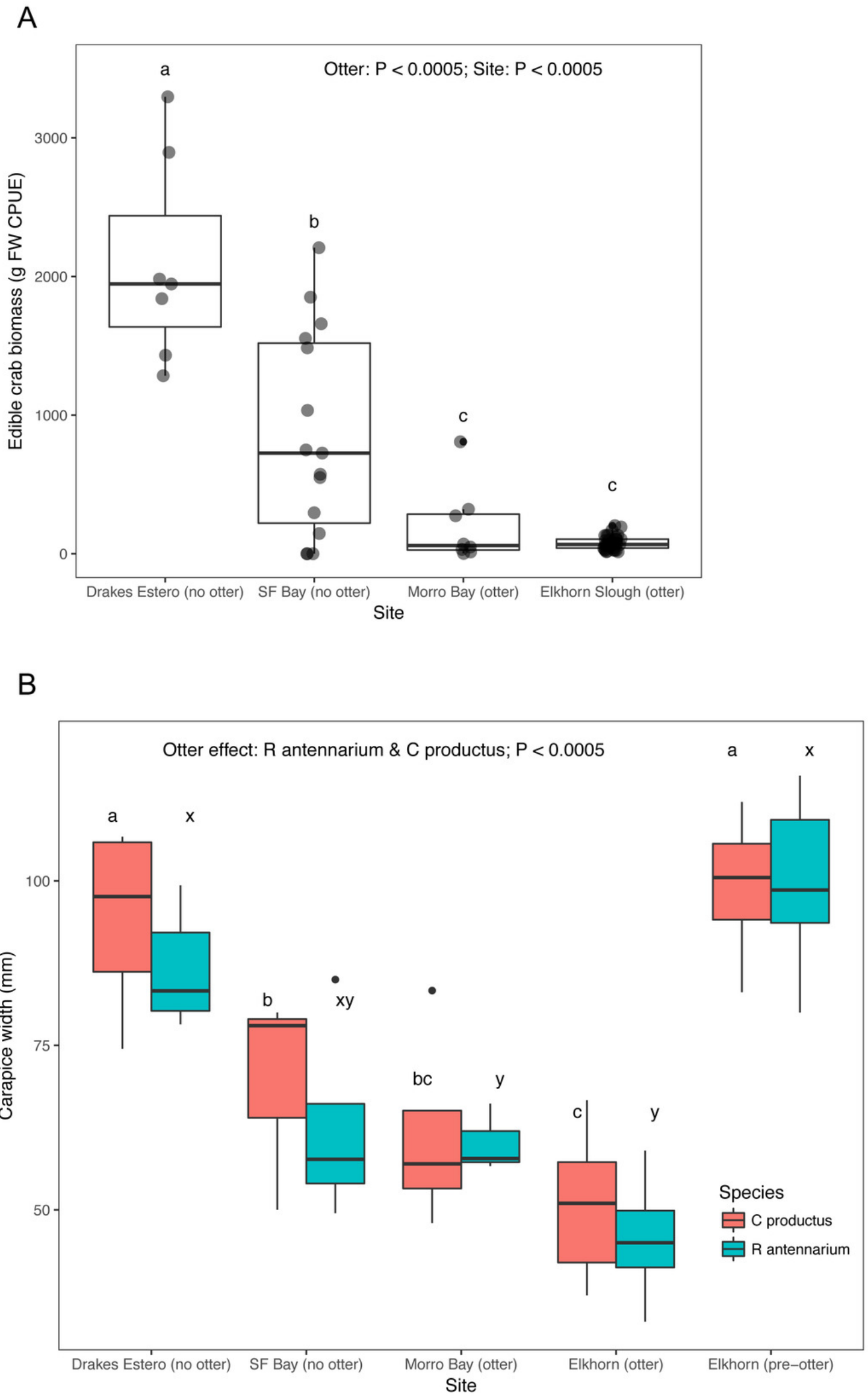


\section{Figure 4}

Sea otters in estuarine and coastal habitats in Elkhorn Slough.

A) resting in an eelgrass bed (Zostera marina), B) hauled out on pickleweed marsh (Salicornia pacifica), C) a sea otter crossing the road between salt marshes. Photo credits: A) J.

Tomoleoni, B) R. Eby, C) N. Fujomoto. 


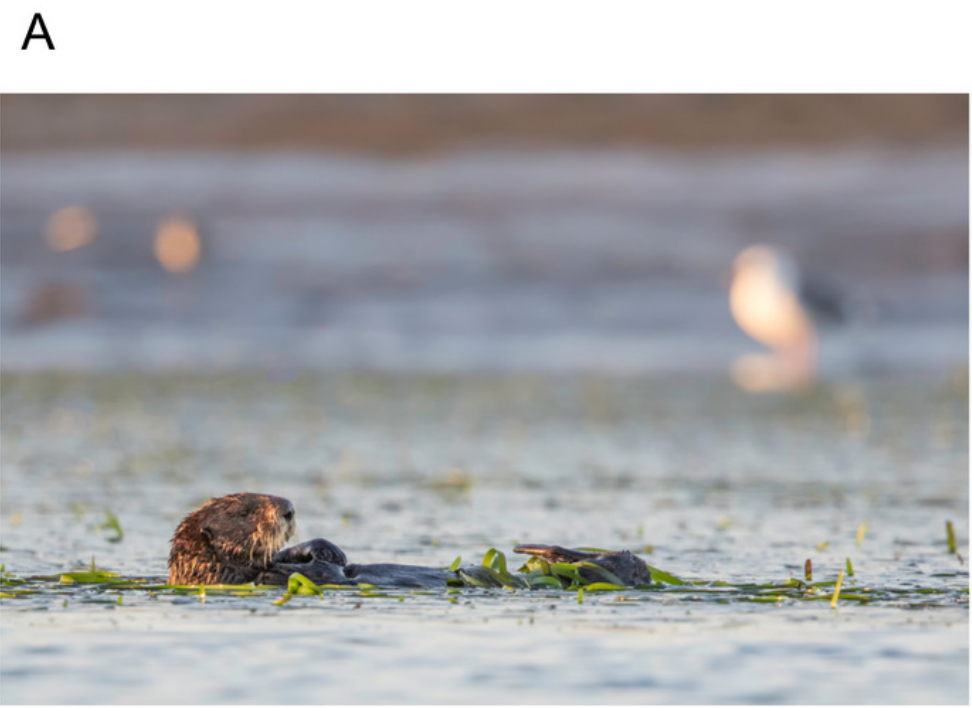

\section{B}

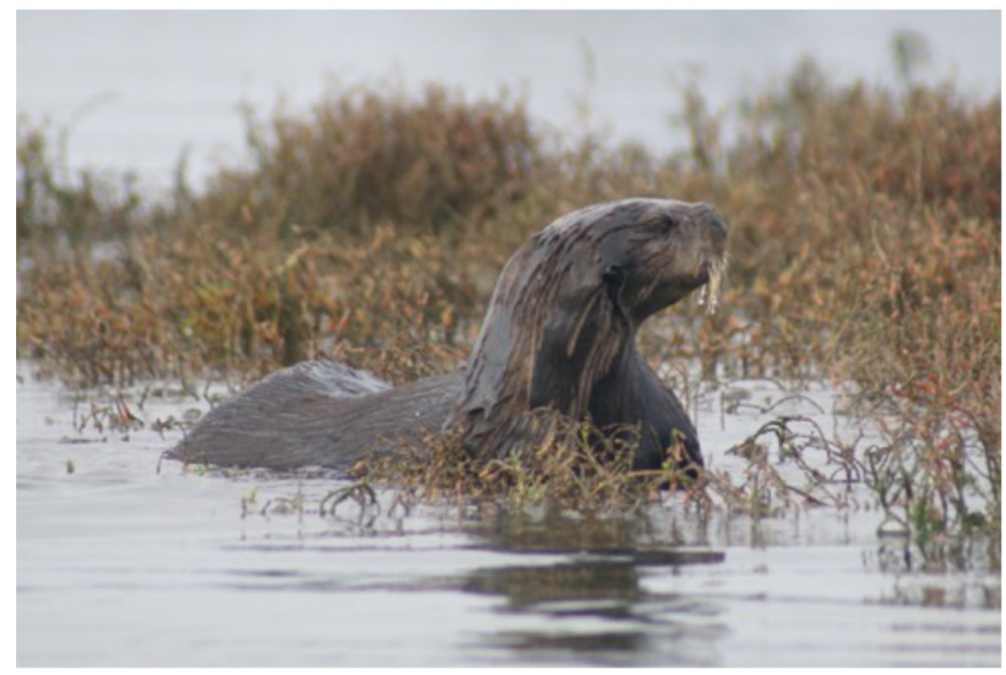

\section{C}

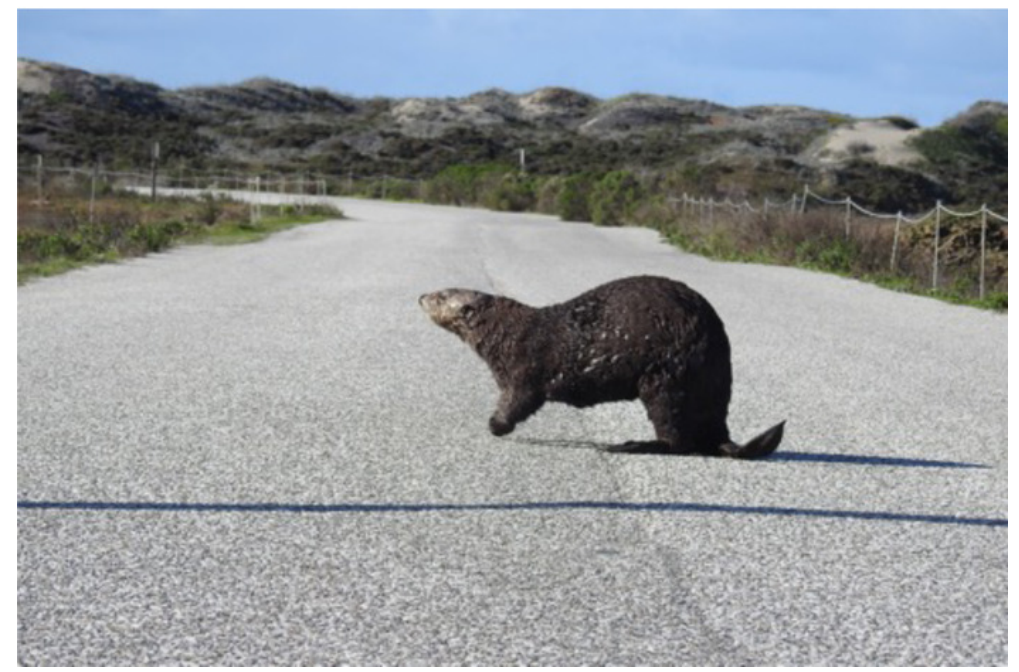

Peer) reviewing PDF | (2019:05:37308:2:2:NEW 4 Oct 2019) 


\section{Table $\mathbf{1}$ (on next page)}

Summary statistics from state-space model of sea otter population dynamics in Elkhorn Slough

(A) Fitted parameters include process error $\left(\mathbf{s}_{\mathbf{p}}\right)$, observer error (expressed as a CV), intrinsic growth rate $(r)$ and carrying capacity of Elkhorn Slough $(K)$. Bayesian diagnostic statistics include Monte Carlo error and "R-hat". (B) Summary statistics for derived parameters, including estimated density at Kfor Elkhorn Slough, lower $95 \% \mathrm{Cl}$ for density at $K$, projected habitat-specific equilibrium densities $\left(K_{h}^{d}\right.$, based on lower $95 \% \mathrm{Cl}$ for estimated $\left.K\right)$, and projected Kvalues for San Francisco Bay (assuming offshore open water densities are 10\% of nearshore open water densities). 
2 Table 1. Summary statistics from state-space model of sea otter population dynamics in Elkhorn 3 Slough. (A) Fitted parameters include process error $\left(\sigma_{\mathbf{p}}\right)$, observer error (expressed as a CV), 4 intrinsic growth rate $(r)$ and carrying capacity of Elkhorn Slough $(K)$. Bayesian diagnostic

5 statistics include Monte Carlo error and "R-hat". (B) Summary statistics for derived parameters, 6 including estimated density at $K$ for Elkhorn Slough, lower 95\% CI for density at $K$, projected

7 habitat-specific equilibrium densities $\left(\mathrm{K}_{\mathrm{h}}^{\mathrm{h}}\right.$, based on lower $95 \%$ CI for estimated $\left.K\right)$, and

8 projected $K$ values for San Francisco Bay (assuming offshore open water densities are 10\% of 9 nearshore open water densities).

$11(\mathrm{~A})$

\begin{tabular}{l|rrrrrrr}
\hline \multicolumn{1}{c|}{ Model } & & & & & & & \\
Parameter & Mean & \multicolumn{1}{c}{ SD } & Lower95 & Median & Upper95 & MCerr & R-hat \\
\hline$\sigma_{\mathbf{p}}$ & 0.31 & 0.08 & 0.16 & 0.3 & 0.48 & 0.002 & 1.003 \\
$\mathbf{C V}$ & 0.1 & 0.08 & 0 & 0.09 & 0.26 & 0.001 & 1.002 \\
$\boldsymbol{r}$ & 0.22 & 0.07 & 0.1 & 0.21 & 0.34 & 0.001 & 1.001 \\
$\boldsymbol{K}$ & 160.37 & 88.09 & 49.45 & 132.65 & 367.45 & 0.893 & 1.001 \\
\hline
\end{tabular}

12

13 (B)

\begin{tabular}{|c|c|c|c|}
\hline \multicolumn{2}{|c|}{$\begin{array}{l}\text { Derived parameters: equilibrium densities } \\
\quad \text { for Otters } * \mathrm{~km}^{-2} \text { (Elkhorn Slough) }\end{array}$} & \multicolumn{2}{|c|}{$\begin{array}{c}K \\
\text { (San Francisco Bay) }\end{array}$} \\
\hline $\mathrm{K}_{\text {mean }}^{\mathrm{d}}$ & 27.1 & & \\
\hline $\mathrm{K}_{\text {lowerCI }}^{\mathrm{d}_{\text {of }}}$ & 8.4 & & \\
\hline $\mathrm{K}_{\text {nearshore }}^{\mathrm{d}}$ & 8.9 & $\mathrm{~K}_{\text {nearshore }}$ & 4228 \\
\hline $\mathrm{K}_{\text {eelgrass }}^{\mathrm{d}}$ & 19.2 & $\mathrm{~K}_{\text {eelgrass }}$ & 1598 \\
\hline $\mathrm{K}_{\text {saltmarsh }}^{\mathrm{d}}$ & 4.5 & $\mathrm{~K}_{\text {saltmarsh }}$ & 425 \\
\hline \multirow[t]{2}{*}{$\mathrm{K}_{\text {offshore }}{ }_{\text {ofs }}$} & 0.9 & $\mathrm{~K}_{\text {offshore }}$ & 356 \\
\hline & & Total & 6607 \\
\hline
\end{tabular}

14

15 
Table 2 (on next page)

List of sea otter prey items found in San Francisco Bay. 
2 Table 2. List of sea otter prey items found in San Francisco Bay.

\begin{tabular}{|c|c|c|c|}
\hline Class & Scientific Name & Common Name & References \\
\hline Asteroidea & Pisaster ochraceus & Seastar & 5 \\
\hline Bivalvia & Clinocarduim nuttallii & Heart cockle & 5 \\
\hline Bivalvia & Macoma spp. & Clam & 5 \\
\hline Bivalvia & Modiolus & Horse mussel & 5 \\
\hline Bivalvia & Mya arenaria & Soft shelled clam & 2 \\
\hline Bivalvia & Mytilus edulis & Bay mussel & 2 \\
\hline Bivalvia & Mytilus galloprovincialis & Mussel & 4 \\
\hline Bivalvia & Ostrea lurida & Olympia oyster & 1 \\
\hline Bivalvia & Protothaca sp. & Littleneck clam & 2 \\
\hline Bivalvia & Saxidomus nuttalli & Washington clam & 3 \\
\hline Bivalvia & Solen sicarius & Razor clam & 5 \\
\hline Bivalvia & Tagelus californianus & Jackknife clam & 2 \\
\hline Bivalvia & Tellina spp. & Clam & 6 \\
\hline Bivalvia & Tivela stultorum & Pismo clam & 3 \\
\hline Bivalvia & Tresus nuttallii & Pacific gaper clam & 2 \\
\hline Bivalvia & Zirfaea pilsbryi & Rough piddock & 5 \\
\hline Decapoda & Cancer productus & Red rock crab & 5 \\
\hline Decapoda & Carcinus maenus & European green crab & 1 \\
\hline Decapoda & Crangon franciscorum & Bay shrimp & 1 \\
\hline Decapoda & Hemigrapsus oregonensis & Shore crab & 1 \\
\hline Decapoda & Metacarcinus gracilis & Graceful crab & 1 \\
\hline Decapoda & Metacarcinus magister & Dungeness crab & 1 \\
\hline Decapoda & Pachygrapsus crassipes & Striped shore crab & 5 \\
\hline Decapoda & Pagurus sp. & Hermit crab & 5 \\
\hline Decapoda & Palaemon macrodactylus & Oriental shrimp & 1 \\
\hline Decapoda & Pugettia producta & Kelp crab & 1 \\
\hline Decapoda & Romaleon antennarium & Pacific red rock crab & 1 \\
\hline Decapoda & Upogebia sp. & Mud shrimp & 5 \\
\hline Echinoidea & a Dendraster excentricus & Sand dollar & 5 \\
\hline Gastropoda & a Ilyanassa obsoleta & Eastern mud snail & 5 \\
\hline Gastropoda & a Nassa fossatus & Mud snail & 5 \\
\hline Gastropoda & a Tegula funebralis & Black turban snail & 5 \\
\hline Gastropoda & a Urosalpinx cinerea & Atlantic oyster drill & 1 \\
\hline Polychaeta & Nereis sp. & Pile worm & 5 \\
\hline
\end{tabular}

3 References: ${ }^{1}$ Boyer K, Zabin C, De La Cruz S, Grosholz E, Orr M, Lowe J, Latta M, Miller J,

4 Kiriakopolos S, Pinnell C, Kunz D, Moderan J, Stockmann K, Ayala G, Abbott R, Obernolte R. 2017. 
5 San Francisco Bay Living Shorelines: Restoring Eelgrass and Olympia Oysters for Habitat and Shore 6 Protection. In: Bilkovic DM, Mitchell MM, La Peyre MK, Toft JD eds. Living Shorelines: The Science 7 and Management of Nature-Based Coastal Protection. CRC Marine Science, 331-360; ${ }^{2}$ Emmett, R.L.,

8 Stone, S.L., Hinton, S.A., Monaco, M.E.M., 1991. Distribution and abundance of fishes and invertebrates 9 in west coast estuaries volume II: species life history summaries. ELMR Rep. No.8. NOAA/NOS

10 Strategic Environmental Assessments Division Rockville, MD., 329 p.; ${ }^{3}$ Skinner, J.E., 1962. An 11 Historical Review of the Fish and Wildlife Resources of the San Francisco Bay Area. Resources Agency 12 of California, Department of Fish and Game, Water Projects Branch, 225 pp.; ${ }^{4}$ Suchanek, T.H., Geller, 13 J.B., Kreiser, B.R., Mitton, J.B., 1997. Zoogeographic distributions of the sibling species Mytilus 14 galloprovincialis and M. trossulus (Bivalvia: Mytilidae) and their hybrids in the North Pacific. Biol. Bull. 15 193, 187-194.; ${ }^{5}$ USGS Western Ecological Research Center,

16 https:/www.usgs.gov/centers/werc/science/san-francisco-bay-benthic-macroinvertebrate-atlas?qt17 science_center_objects $=0 \# q t-s c i e n c e$ center_objects; ${ }^{6}$ Hunt, J.W., Anderson, B.S., Phillips, B.M., 18 Tjeerdema, R.S., Taberski, K.M., Wilson, C.J., Puckett, H.M., Stephenson, M., Fairey, R., Oakden, J., 19 2001. A large-scale categorization of sites in San Francisco Bay, USA, based on the sediment quality 20 triad, toxicity identification evaluations, and gradient studies. Environ. Toxicol. Chem. 20, 1252-1265. 